\title{
Helium, iron, and electron particle transport and energy transport studies on the TFTR tokamak
}

\author{
E.J. Synakowski, P.C. Efthimion, G. Rewoldt, B.C. Stratton, W.M. Tang, \\ B. Grek, K.W. Hill, R.A. Hulse, D.W. Johnson, M.W. Kissick*, D.K.
} Marisfield, D. McCune, D.R. Mikkelsen, H.K. Park, A.T. Ramsey, M.H. Redi, S.D. Scott, G. Taylor, J. Timberlake, M.C. Zarnstorff

Princeton Plasma Physics Laboratory, Princeton University, Princeton, New Jersey 08543

Results from helitm, iron, and electron transport studies on TFTR [Plasma Phys. Controlled Nucl. Fusion Research 1, 51 (1986)] in L-mode and Supershot deuterium plasmas with the same toroidal field, plasma current, and neutral beam heating power are presented. They are compared to results from thermal transport analysis based on power balance. Particle diffusivities and thermal conductivities are radially hollow and larger than neoclassical values, except possibly near the magnetic axis. The ion channel dominates over the electron shannel in both particle and thermal diffusion. A peaked helium profile, supported by inward convection that is stronger than predicted by neoclassical theory, is measured in the Supershot. The helium profile shape is consistent with predictions from quasilinear electrostatic drift-wave theory. While the perturbative particle diffusion coefficients of all three species are similar in the Supershot, differences are found in the L-Mode. Quasilinear theory calculations of the ratios of impurity diffusivities are in good accord with measurements. Theory estimates indicate that the ion heat flux should be larger than the electron heat flux, consistent with power balance analysis. However, theoretical values of the ratio of the ion to electron heat flux can be more than a factor of three larger than experimental values. A correlation between helium diffusion and ion thermal transport is observed and has favorable implications for sustained ignition of a tokamak fusion reactor.

* University of Wisconsin, Madison Wisconsin 53706 


\section{INTRODUCTION}

Particle and energy transport in tokamak plasmas have long been subjects of vigorous investigation. Local relationships between particle transport, particularly helium transport, and energy transport may ultimately indicate whether a tokamak operating in a given confinement regime is a viable candidate as a future fusion reactor. Also, a characterization of the local transport of several plasma species as well as the relationship between particle and energy transport may give insight regarding the nature of the underlying transport mechanisms. Recent examples illustrate that the state of the art in transport studies has evolved to the point where radially resolved transport measurements of electron perturbations, ${ }^{1}$ low- $Z^{2,3,4}$ and high- $Z^{5}$ impurities, and energy $6,7,8,9$ are possible. In addition, recent developments in transport theory provide tools that can be brought to bear on transport issues, allowing the local measurements to be a means of not only characterizing tokamak plasma transport but also of testing transport models.

Peaked density Supershot 10 and L-Mode plasmas on TFTR are known to have markedly different energy confinement times, electron and ion temperature profiles, and electron density profiles. It is natural to ask about the local characteristics of the accompanying transport, and in particular to ask whether the changes between the two regimes are reflected in differences in the local energy transport, particle transport, or both. Also, just as energy flows in the ion and electron channels are known to be different in a given plasma, there is no reason to believe that in a multispecies plasma the particle transport of each species should be the same. This is of practical importance when extrapolating particle and energy transport measurements to future tokamak reactor scenarios: if helium and electron particle transport are significantly different in a given regime, then comparing electron transport rates to thermal transport rates is potentially misleading.

This work has four intertelated aims. Transport studies of TFTR Supershot and LMode plasmas with the same plasma current, toroidal field, and neutral beam heating power are presented. The first goal is to perform as complete a characterization as possible of the local transport of thermal helium, iron, and electrons in both confinement regimes. It is demonstrated that it is possible to measure differences in the local particle transport of different species in the same plasma condition and differences in transport of a given species in the two plasma types. Transport of $\mathrm{He}^{2+}$ (introduced by a small gas puff) and $\mathrm{Fe}^{24+}$ (introduced by laser blowoff) was studied using charge exchange recombination 
spectroscopy (CHERS). ${ }^{11,12}$ Electron transport was studied in two complementary ways. A ten channel Micheison infrared interferometer (MIRI) ${ }^{13}$ was used to measure the perturbed electron flux ${ }^{1}$ from the same helium puff used for the $\mathrm{He}^{2+}$ studies. Examining the perturbed electron and $\mathrm{He}^{2+}$ responses following the same gas puff provides an unambiguous comparison of the perturbative transport of the two species. Electron particle balance analysis was also performed on the same discharges, permitting a comparison of perturbative and particle balance analysis results. This is important since the relationship between the two depends on the underlying transport mechanisms.

Second, particle transport results are compared to local energy transport results from power balance analysis. The characteristics of the ion and electron channels in both particle and energy transport are examined. Also, similarities in behavior of particle and energy diffusion in going from the Supershot to the L-Mode are discussed.

Third, these particle and energy transport results are used as a test bed for a transport model based on quasilinear electrostatic drift-wave-type instabilities. ${ }^{14}$ Results from theory calculations of the ratios of particle and thermal fluxes for both plasmas at the plasma halfradius and near the magnetic axis are presented. These provide a local test of the theory over a wide range of gradients of temperature, electron density, and impurity density. Comparisons are made with this theoretical model because it is complete enough to enable predictions of the ratios of thermal and particle transport coefficients and fluxes of a multispecies plasma in a toroidal geometry.

Finally, implications for helium ash transport in future tokamak fusion reactors which arise from measured correlations between local energy transport and local helium transport in the core of these TFTR plasmas are discussed. The relative importance of helium transport rates (both diffusive and convective), the thermal helium source profile and source rate, and thermal conduction in determining the depletion of deuterium and tritium is examined given the transport coefficients measured.

Section II contains a description of the experiment and results. There, the L-mode and Supershot plasmas are described. Similarities and differences in the particle transport coefficients of the three species are discussed, and comparisons with the thermal conductivities are made. In Section III, the quasilinear drift wave model is outlined and the results of calculations of ratios of fluxes and transport coefficients are presented and compared to measured quantities. The implications of the measured correlation between helium particle transport and energy transport for helium ash transport in a future tokamak 
reactor are explored in Section IV. Conclusions are outlined in Section V. Appendix A contains discussion of the details of the measurement techniques used in the impurity measurements. Appendix $\mathrm{B}$ contains a discussion of the interpretation of perturbative transport coefficients of trace and bulk species.

\section{DESCRIPTION OF THE EXPERIMENT AND RESULTS}

\section{A. Plasma Description}

Both the L-mode and Supershot plasmas had a toroidal field of $4.8 \mathrm{~T}$, a plasma current of 1.0-1.1 MA, and 12-13 MW of balanced neutral deuterium beam injection. The plasma major radius was $2.45 \mathrm{~m}$, and the minor radius was $0.80 \mathrm{~m}$. Typical electron density, electron temperature, and ion temperature profiles for both the L-mode and Supershot are shown in fig. 1. The electron density was measured by a ten-channel infrared interferometer, and electron temperature was measured by electron-cyclotron emission and Thomson scattering. Ion temperatures were measured by charge exchange recombination spectroscopy (CHERS) ${ }^{15}$, viewing the $5292 \AA(n=8-7)$ line of $C^{5+}$ excited by charge exchange recombination of $C^{6+}$ with heating beam neutrals. $Z_{e f f}(r)$ was measured both with a tangentially viewing visible bremsstrahlung (VB) array and with radial profiles of $\mathrm{C}^{6+}$, normalized to the central VB value, obtained with CHERS (carbon is the dominant impurity in most TFTR discharges). The central line-integrated electron density is shown in fig. 2 for the Supershot. A $24 \mathrm{~ms}$ helium puff was introduced into the plasma about halfway into the neutral beam pulse, resulting in a small perturbation in the line-averaged electron density ( $<5 \%$ ). The drop in $\mathrm{T}_{e}$ after the puff was less than $3 \%$ at all radii. For the iron measurements, iron was injected with the laser blowoff technique during the electron density flattop. For these plasmas, the density perturbation following iron injection was less than $1 \%$. The prompt perturbation on the electron temperature after iron injection was less than $3 \%$ for the L-Mode and less than $1 \%$ for the Supershot.

For the L-Mode, data from eight nearly identical discharges were averaged together so as to improve statistics of the helium transport and electron transport data. For the Supershot, fourteen nearly identical plasmas were used. Smaller ensembles were averaged together for the iron data. For the purpose of comparison with local electrostatic turbulence-based models and for reproducibility, the plasmas used in the transport analysis were chosen to be as free as possible of MHD activity, with the exception of small sawteeth 
present in the $\mathrm{L}$-mode. The normalized sawtooth inversion radius $\mathrm{r}_{\mathrm{inv}} / \mathrm{a}$ was 0.13 , and the measured change in electron temperature $\Delta \mathrm{T}_{e}(0) / \mathrm{T}_{\mathrm{e}}(0)$ was less than $10 \%$. Their impact on the transport measurements was minimal, as is discussed below. For the Supershot, sawteeth were suppressed.

\section{B. Methods of Analysis of Particle and Thermal Fluxes \\ 1. Perturbative Helium, Iron, and Electron Measurements}

For all particle transpor measurements, the flux is evaluated by solving the continuity equation

$\partial n / \partial t=-\nabla \cdot \Gamma+S$.

It is assumed that the impurity fluxes can be described as diffusive and convective flows, i.e.

$\Gamma_{z}(r, t)=-D_{z}(r) \nabla n_{z}(r, t)+V_{z}(r) n_{z}(r, t)$

For fully-stripped helium, the source and sink $\mathrm{S}_{\mathrm{He} 2+}$ is governed by ionization of $\mathrm{He}^{+}$and recombination of $\mathrm{He}^{2+}$. Modelling with the MIST ${ }^{16}$ impurity transport code, which solves the continuity equation given a source at the plasma boundary, indicates that $\mathrm{S}_{\mathrm{He} 2+}$ plays a small role in the continuity equation for $r / a<0.8$ compared to the transport of the helium ions following the gas puff.

For both the helium and iron measurements, the CHERS spectrometer viewed a coinjecting neutral beam line in the midplane (fig. 3). For all CHERS measurements, fiber optics bring the light from the plasma to a Czerny-Turner spectrometer. Sightline-neutral beam intersection radii were spaced by approximately $0.1 \mathrm{~m}$, providing up to eight radial measurements in this $0.80 \mathrm{~m}$ minor radius plasma. The resolution in major radius was $0.02-0.03 \mathrm{~m}$ per channel.

For both the steady-state and perturbative helium measurements, the $n=4-3,4686 \AA$ $\mathrm{He}^{+}$line, excited by charge exchange with beam neutrals, was used to measure the $\mathrm{He}^{2+}$ density profile shape (see Appendix A). Since CHERS provides local information about 
the time histories of the helium density following the puff, both the helium diffusivity $\mathrm{D}_{\mathrm{He}}$ and convective velocity $V_{\mathrm{He}}$ in the source-free region are evaluated by inferring the helium flux $\Gamma_{\mathrm{He}}$ directly from the measured time-dependent $\mathrm{He}^{2+}$ profiles. The flux, normalized to the local density, and the local scale length measurements are then used to evaluate the transport coefficients directly. ${ }^{17}$ Plots of $\Gamma_{\mathrm{He}} / n_{\mathrm{He}}$ as a function of $\nabla n_{\mathrm{He}} / n_{\mathrm{He}}$ at one minor radius are shown in fig. 4 for the L-mode. The normalized flux obeys a linear behavior, consistent with expectations for a trace impurity and time-independent transport coefficients. The diffusion coefficient $D_{H e}$ is the absolute value of the slope of the best-fit line, and the convective term $V_{\mathrm{He}}$ is given by the $y$-intercept. Negative values of $\mathrm{V}_{\mathrm{He}}$ are defined to be inward. The main contributors to the uncertainty in the determination of the transport coefficients are noise in the measured $\Gamma_{\mathrm{He}} / n_{\mathrm{He}}$ and $\nabla n_{\mathrm{He}} / n_{\mathrm{He}}$ and systematic uncertainties in the changes of these two quantities. These systematic errors are due to uncertainties in the profile shape arising from errors in the beam stopping cross sections and the plume correction.

This local analysis of the helium data was chosen to obviate difficulties in predictive modelling of the helium source and fully stripped helium time behavior following a gas puff. The success of predictive modelling with MliT of a highly recycling gas such as helium depends heavily on the ability to model the edge correctly. In these experiments, the time history of the helium source after the puff was measured by observing the $304 \AA$ $\mathrm{He}^{+}$line $(n=2-1)$. A range of values of $\mathrm{V}_{\mathrm{He}}, \mathrm{D}_{\mathrm{He}}$, recycling coefficient $\mathrm{R}_{\mathrm{He}}$, recycling neutral energy $E_{0}$, and edge plasma parameters such as scrapeoff layer lengths and parallel transport times can result in predicted time histories that are in fact within the noise of the data from a single discharge. However, averaging data from the fourteen nearly identical Supershot plasmas cleaned up the CHERS and source measurements considerably. This revealed small features in the time evolutions that were impossible to reconcile with the model. No values of $\mathrm{V}_{\mathrm{He}}, \mathrm{D}_{\mathrm{He}}, \mathrm{R}_{\mathrm{He}}, \mathrm{E}_{0}$, and edge plasma parameters could be found to simultaneously reproduce the time histories measured for the outer CHERS channels and the measured source behavior in the first $30-50 \mathrm{~ms}$ after the puff while still being consistent with the long-time behavior after $150 \mathrm{~ms}$. Candidates for the inadequacy of the predictive modelling are poor spatial resolution of the CHERS measurements and particle source measurements in the scrapeoff region of the plasma, lack of knowledge of any toroidal and poloidal asymmetries of the helium source time behavior, and possible time dependence of the helium recycling coefficient during the puff itself. 
This issue is not important for iron since it has a very low recycling coefficient: the neutral iron source is essentially a delta-function in time. Helium-like iron $\left(\mathrm{Fe}^{24+}\right)$ was chosen for iron transport measurements because it is the dominant iron charge state in the core region of the TFTR discharges studied. Iron measurements were made using the 5001 $\AA$ line of $\mathrm{Fe}^{23+}(n=19-18)$, excited by charge exchange with heating beam neutrals (Appendix A). Because ionization and recombination for an iron ion (the source term in eq. 1) are important for the entire plasma cross section, MIST was used to solve the continuity equation and to model the time evolutions of the $\mathrm{Fe}^{24+}$ density following laser blowoff. The iron atom source is an instantaneous burst of atoms that are assumed to be monoenergetic with an energy of $3 \mathrm{eV}$. The atoms are ionized in the region between 0.75 $\mathrm{m}$ and $0.80 \mathrm{~m}$, well outside the observed region. ${ }^{18}$ Varying the energy of the incoming atoms between $1 \mathrm{eV}$ and $10 \mathrm{eV}$, and thus the source radius, does not make a significant difference in the predicted time evolutions or profiles of the core ionization states observed here. The results are insensitive to assumptions about the width of the scrapeoff region in the range of $0-0.10 \mathrm{~m}$. A value of $0.05 \mathrm{~m}$ was used here. The relevant atomic physics rates (electron impact ionization, dielectronic recombination, radiative recombination and charge exchange recombination) are as described in reference 5. The effect of uncertainties in these rates on the MIST predictions was evaluated by making reasonable variations of the rates and comparing the results. This indicated that the shape of the time evolutions of the $\mathrm{Fe}^{24+}$ density at the observed radii are insensitive to uncertainties in the rates but that the profile shape is sensitive. In the modelling, $\mathrm{D}_{\mathrm{Fe}}$ was not constrained to have any particular radial form, but $\mathrm{V}_{\mathrm{Fe}}$ was parameterized as $\mathrm{V}_{\mathrm{Fe}}(\mathrm{r})=-\mathrm{c}_{\mathrm{V}}\left(2 \mathrm{D}_{\mathrm{Fe}}(\mathrm{r}) / \mathrm{a}\right)(\mathrm{r} / \mathrm{a})$. The data were modeled by varying $D_{\mathrm{Fe}}$ and $c_{\mathrm{v}}$ to match the observed time evolutions of the $\mathrm{Fe}^{24+}$ density at the observed radii. The measured and predicted profile shapes were then checked for reasonable agreement.

The small amount of helium gas puffed into these plasmas to determine the helium particle transport also serves as the source of the electron density perturbation. The time evolution of the density profile measured with the 10 channel far-infrared laser interferometer is used to solve the particle balance equation within the TRANSP analysis code. 19 For these plasmas, the neutral-beam fueling rate profile is calculated with a Monte Carlo beam deposition algorithm in the code. The wall source is calculated from the total number of particles in the plasma and an estimate of the particle confinement time. The particle confinement time during the helium puff is assumed to be equal to the steady state 
value preceding the puff. The paricle confinement time before the helium puff is calculated from the particle balance equation using the brightness of the $D_{\alpha}$ line $(6562 \AA)$ to provide the wall source. A ter the helium puff perturbation the particle confinement time based upon the $D_{\alpha}$ emission is the same as the value before the puff. The solution of the particle balance equation provides the electron particle flux, $\Gamma_{\mathrm{e}}(r, t)$, as a function of plasma radius and time. The local transport coefficients are then the coefficients in a linear multiple regression with $\Gamma_{\mathrm{e}}$ as the dependent variable ${ }^{1}$ :

$$
\delta \Gamma_{e}=\left(\partial \Gamma_{e} \partial \nabla n_{e}\right) \delta \nabla n_{e}+\left(\partial \Gamma_{e} / \partial n_{e}\right) \delta n_{e}
$$

where the symbols $\delta \nabla n_{e}$ and $\delta n_{e}$ refer to the perturbed electron density gradient and density, respectively, and $\partial \Gamma_{\mathrm{e}} / \partial \nabla \mathrm{n}_{\mathrm{e}}$ and $\partial \Gamma_{\mathrm{e}} / \partial \mathrm{n}_{\mathrm{e}}$ are the transport coefficients. The coefficients $\partial \Gamma_{e} / \partial \nabla n_{e}$ and $\partial \Gamma_{e} / \partial n_{e}$ have the units of particle diffusivity and convection. Because these coefficients are not necessarily the steady state coefficients and may be nonlinear (e.g. $\partial \Gamma_{e} / \partial \nabla n_{e}$ and $\partial \Gamma_{e} / \partial n_{e}$ are functions of either $\nabla n_{e}$ or $n_{e}$ ) the coefficients are left as the terms in the Taylor series expansion. This regression is applied at each radius over the time of the density perturbation to produce transport coefficients as a function of plasma radius. In fact, the regression is applied to the total parameters instead of the perturbed parameters, because regression analysis removes the steady state component of the dependent and independent variables and makes fits based upon the change of the parameters. This was verified by completing the regression analysis on the total and the perturbed variables and exactly the same coefficients were obtained. Previously, the regression was applied to the equation $\delta \Gamma_{e} / n_{e}=\left(\partial \Gamma_{e} / \partial \nabla n_{e}\right) \delta \nabla n_{e} / n_{e}+\left(\partial \Gamma_{e} / \partial n_{e}\right) \cdot{ }^{17}$ However, it was observed that for small electron density perturbations, $n_{e}$ and $\nabla n_{e}$ are decorrelated parameters compared to the quality of the regression fits and thus they may be treated as independent variables. Using both terms results in better fits and does not include the overall residue from the fits in the coefficient $\delta \Gamma \Gamma^{/ n_{e}}$ The electron diffusivity inferred from the perturbation is noted here as $D_{e}^{p} \equiv-\partial \Gamma_{e} / \partial \nabla n_{e}$. This may be quite different from the steady-state diffusivity (see Section II.C.1 and Appendix B).

\section{Power and Particle Balance Analysis}

Beam energy deposition and thermal heat fluxes were calculated using the transport code TRANSP using experimentally measured radial profiles of plasma parameters 
including $n_{e}, T_{c}, T_{i}$, and $Z_{c f f}$. To avoid confusion regarding convective vs. diffusive heat fluxes, we define an effective thermal conductivity $\chi^{\text {eff: }}$

$\mathrm{Q}_{\mathrm{e}} \equiv-\chi_{\mathrm{e}}^{\mathrm{eff}} \mathrm{n}_{\mathrm{e}} \nabla \mathrm{T}_{\mathrm{e}}$,

$Q_{i} \equiv-\chi_{i}^{e f f}\left(\sum_{j} n_{j} \nabla T_{i}\right)$,

$\mathrm{Q}_{\mathrm{i}}+\mathrm{Q}_{\mathrm{e}} \equiv-\chi_{\text {tot }}^{\text {eff }}\left(\mathrm{n}_{\mathrm{e}} \nabla \mathrm{T}_{\mathrm{e}}+\sum_{\mathrm{j}} \mathrm{n}_{\mathrm{j}} \nabla \mathrm{T}_{\mathrm{i}}\right)$

where $\mathrm{Q}_{i}$ and $\mathrm{Q}_{e}$ are the ion and electron heat fluxes, respectively. The sum is over the thermal ions, including impurities. In the Supershot, the heat flux is not purely conductive: convection is an important heat transport mechanism, especially near the magnetic axis. However, power balance analysis shows that the thermal transport coefficients with and without convection subtractedexhibit the same trends between L-Mode and Supershot. Error estimates of these power balance calculations were obtained by performing 64 transport analyses with the steady-state transport code SNAP. The measured background plasma profiles and other input data were varied within their ranges of uncertainty by Monte Carlo sampling a Gaussian distribution for both statistical and systematic errors. ${ }^{8}$

TRANSP was used to evaluate the electron particle flux by calculating the electron source rate from the beam neutrals and using the measured source rate from $D_{\alpha}$ measurements at the plasma edge. An effective diffusivity is defined using the calculated flux and the measured electron density profile:

$\Gamma_{\mathrm{e}} \equiv-\mathrm{D}_{\mathrm{e}}^{\mathrm{eff}} \nabla \mathrm{n}_{\mathrm{e}}$

This representation of the equilibrium particle flux does not distinguish between diffusive and convective contributions to the total particle flux. Still, it is a useful quantity because depending on the functional dependency of the particle flux on perturbed plasma quantities, $\mathrm{D}_{\mathrm{e}}^{\text {eff }}$ and $\mathrm{D}_{\mathrm{e}}^{\mathrm{p}}$ may be related, as discussed below.

\section{Particle and Thermal Transport Measurement Results 1. Inferences from Steady-State Radial Helium Profiles}

Measured profiles of the fully-stripped helium density $n_{\mathrm{He}}$ and concentration $n_{\mathrm{He}}(\mathrm{r}) / \mathrm{n}_{\mathrm{e}}(\mathrm{r})$ obtained $150 \mathrm{~ms}$ after the puff are shown in fig. 5 . Since the absolute value of both quantities is not only a function of transport but also of recycling properties and gas 
puff size, both $n_{\mathrm{Hc}}(r)$ and $n_{\mathrm{Hc}}(r) / n_{\mathrm{c}}(r)$ are normalized to central values. For both the $\mathrm{L}$ mode and Supershot, the shape of the helium profile remained constant after $150 \mathrm{~ms}$, although the amplitude of the profile in the Supershot decreased in time as a result of pumping of the helium by the well-conditioned bumper limiter. The profile shape determination includes contributions to the spectral line brightness from electron-impact excitation of $\mathrm{He}^{+}$ions formed after the charge exchange event (Appendix A). ${ }^{13}$ The shaded regions represent the effects of published uncertainties in the beam stopping cross sections, charge exchange excitation rates for the three beam species, and electron impact excitation rates relevant to plume brightness calculations. These systematic effects affect the Supershot and L-Mode profiles shapes in the same sense, implying that differences between the Supershot and L-Mode in $n_{\mathrm{He}}(r)$ and $n_{\mathrm{He}}(r) / n_{e}(r)$ profiles are real.

The helium density profile is peaked compared to the electron density profile in the Supershot. This is despite the fueling of electrons in the central region of the plasma from neutral beams and indicates that the helium transport must differ from the electron transport. Also, because the Supershot $\mathrm{He}^{2+}$ profile is peaked on axis in the source-free region, inward impurity convection must play an important role in the transport process. The $\mathrm{C}^{6+}$ profile (as measured with CHERS) has a similar central peak and relatively flat pedestal in the outer half of the plasma as well. The similarity between the steady-state $\mathrm{He}^{2+}$ profile and the $\mathrm{C}^{6+}$ profile is encouraging since the carbon measurements are much less prone to the effects of ion plume emission. Also, $Z_{\text {eff }}$ profiles measured with a midplane visible bremsstrahlung array are consistent with these measured impurity profiles. For these plasmas, the broad L-Mode helium profile and the centrally peaked Supershot helium profile are predicted by quasilinear drift-wave theory, as is discussed in Section III.

\section{Steady-State Particle and Energy Transport}

In this section we confine the discussion of diffusivities to transport coefficients that are interpreted as being steady-state values (see Appendix B). The particle transport coefficients $D_{\mathrm{He}}, \mathrm{D}_{\mathrm{Fe}}$ and $\mathrm{D}_{\mathrm{e}}^{\text {eff }}$ are shown in fig. $6(\mathrm{a}-\mathrm{c})$. The thermal transport coefficients $\chi_{\mathrm{i}}^{\text {eff }}, \chi_{\mathrm{e}}^{\text {eff }}$, and $\chi_{\text {tot }}^{\text {eff }}$ are shown in fig. $7(\mathrm{a}-\mathrm{c})$. All of these transport coefficients are radially hollow and are larger than neoclassical values, except possibly near the magnetic axis.

For both plasmas, the helium and iron diffusivities $D_{\mathrm{He}}$ and $D_{\mathrm{Fe}}$ are larger than the effective electron diffusivity $\mathrm{D}_{\mathrm{e}}^{\text {eff }}$. This is similar to the ordering of the ion and electron thermal transport coefficients, i.e. $\chi_{i}^{\text {eff }}>\chi_{e}^{\text {eff }}$ (fig. 7) for the L-Mode and Supershot. The 
dominance of the ion thermal channel over the electron thermal channel is reflected in the fact that, according to power balance calculations, $Q_{i}>Q_{e}$ for most of the plasma cross section of both plasmas. The dominance of the ion channels and electron channels with respect to particle and thermal fluxes is incompatible with simple models based on magnetic stochasticity. However, it is qualitatively consistent with expectations based on the quasilinear electrostatic drift-wave transport model discussed in Section III.

The helium diffusivity $\mathrm{D}_{\mathrm{He}}$ is reduced in the inner half of the Supershot as compared to the L-Mode (fig. 6(a)). Also, $\mathrm{D}_{\mathrm{e}}^{\mathrm{eff}}$ is smaller in the Supershot as compared to the L-Mode (fig. 6(c)). If helium transport is similar to the transport of the working thermal ions, then one characteristic of the improvement in particle confinement in the Supershot is the reduction in the working particle diffusivities in the plasma core. The reduction in $D_{\mathrm{He}}$ is similar to the reduction in $\chi_{i}^{e f f}$ in the Supershot as compared to the L-Mode. ${ }^{20}$ The similarity in magnitude and behavior of $D_{\mathrm{He}}$ and $\chi_{i}^{\text {eff }}$ between the two confinement regimes suggests that a link exists between ion thermal and particle transport. The similarity between $\mathrm{D}_{\mathrm{He}}$ and the $\chi$ 's has previously been reported for rotating L-Mode plasmas on TFTR $^{2}$ and appears to be a feature of TFTR plasmas in general. The fact that $\chi_{i}^{\text {eff }}>\chi_{e}^{\text {eff }}$ and $Q_{i}>Q_{e}$ implies that $\chi_{i}^{\text {eff }}$ is also similar in behavior and magnitude to $\chi_{\text {tot }}^{\text {eff }}$ (fig. $7(c)$ ). Implications of the resultant similarity between $D_{\mathrm{He}}$ and $\chi_{\text {tot }}^{\text {eff }}$ are generally favorable for helium ash accumulation issues in future tokamak reactors and are discussed in Section IV.

Not all impurities transport in the same way. The reduction found in the $\mathrm{D}_{\mathrm{He}}$ when going from L-Mode to Supershot is not found for $\mathrm{D}_{\mathrm{Fe}}$ (fig. 6(b)). In fact, the change in $D_{F e}$ is in the opposite sense of what might be naively expected. While $D_{\mathrm{He}}$ is similar in shape and magnitude to $D_{\mathrm{Fe}}$ in the Supershot, $\mathrm{D}_{\mathrm{Fe}}<\mathrm{D}_{\mathrm{He}}$ in the inner third of the plasma of the L-mode plasma. These differences in helium and iron diffusion in the L-Mode are in fact anticipated by the quasilinear drift-wave transport model (Section III). The experimental result serves as a caution against making generalizations about particle transport from measurements of a single species.

To confirm the validity of this result, MIST modelling of the iron data was performed under a variety of assumptions as to the shape and magnitude of $\mathrm{D}_{\mathrm{Fe}}$ and $\mathrm{V}_{\mathrm{Fe}}$. No form of $\mathrm{D}_{\mathrm{Fe}}$ reproduced the data under the assumption that $\mathrm{V}_{\mathrm{Fe}}=\mathrm{V}_{\mathrm{He}}$. Also, no satisfactory simulations were obtained for any form of $\mathrm{V}_{\mathrm{Fe}}$ assuming that $\mathrm{D}_{\mathrm{Fe}}=\mathrm{D}_{\mathrm{He}}$, indicating that the conclusion that $D_{\mathrm{Fe}}<D_{\mathrm{He}}$ in the core of the L-Mode plasma is not due to errors in the modelling. 
Sawtooth oscillations, present in the L-Mode but suppressed in the Supershol, are expected to enhance the diffusivity of impurities in some circumstances. ${ }^{21}$ Here, however, sawtooth effects are measured to be small in the L-mode. The sawtooth inversion radius for the $L$-mode was $r / a \sim 0.13$. Helium data averaged together from discharges with coincident sawtooth crash times were found to be absent of any signs of modulation of the local density except at $\mathrm{r} / \mathrm{a} \sim 0$. There, $\Delta \mathrm{n}_{\mathrm{He}} \mathrm{n}_{\mathrm{He}}$ across the sawtooth crash was $<10 \%$. The transport coefficients near the magnetic axis derived from the density rise during crashfree portions of the sawtooth cycle were found to be the same, within statistical errors, as those obtained during longer periods of the cycle that included crashes. The lack of significant changes in the measured diffusivity as a result of sawteeth is not unexpected in this particular case since the transport time scale between sawtooth crashes within the sawtoothing region is rapid compared to the sawtooth period. In the case of iron, modelling with MIST indicates that sawteeth do not effect the time scale of the central iron density decay significantly, again owing to the rapid transport as compared to the sawtooth period. 5

The helium convective velocity $\mathrm{V}_{\mathrm{He}}$ in the Supershot is inward and larger than neoclassical values for $r / a<0.4$ (fig. 8(a)). Helium convection in the Supershot characterized by two regions inside the scrapeoff. Values consistent with neoclassical predictions are found for $0.4<\mathrm{r} / \mathrm{a}<0.8$, although anomalous values cannot be ruled out. However, inward convective velocities larger than neoclassical values 22 are inferred for $r / a$ $<0.4$. The L-Mode values are more uncertain (fig. 8(b)) because of the larger uncertainty in the helium profile scale length. For the L-Mode, anomalous values of $\mathrm{V}_{\mathrm{He}}$ (both inward and outward) are within the uncertainties of the measurement, as are neoclassical values. Although the predominantly systematic errors are larger in the L-Mode than in the Supershot, the radial structure of the Supershot $\mathrm{V}_{\mathrm{He}}$ is not present in the family of possible radial forms of the $\mathrm{L}-\mathrm{Mode} \mathrm{V}_{\mathrm{He}}$, indicating that there are changes in convective helium transport between the two regimes.

Using the parameterized form of $\mathrm{V}_{\mathrm{Fe}}$, trends in iron convective transport between the L-Mode and Supershot can be discerned. For iron, proper fits of the data are obtained only if $\mathrm{V}_{\mathrm{Fe}}$ is assumed to be inward and larger than neoclassical values for both cases, and larger in magnitude for the Supershot than the L-Mode (see fig. 9).

Although the Supershot helium profile shape is roughly what might be expected from simplified neoclassical considerations, i.e. $n_{\mathrm{He}}(r) \propto n_{e}{ }^{2}(r)$, the measurements of the 
transport coefficients clearly indicate that the transport is not neoclassical. Similarity with neoclassical predictions of the profile shape must be regarded as coincidental and cautions against inferring neoclassical behavior of impurities from profile shape measurements alone.

\section{Perturbative Electron Transport Measurements and Relationships With} Steady-Siate Transport

Comparisons of perturbative electron transport measurements and helium transport measurements yield some surprises. The electron transport following the perturbation was found to be different from the helium transport in the L-Mode, even though both perturbations were from the same gas puff. The density rise of ilectrons and $\mathrm{He}^{2+}$ following the puff into the L-mode plasma is shoivn in fig. 10(a). The perturbed densities are normalized to long-time values, and the steady-state background levels are subtracted from them. The data are averaged over the same eight $L$-mode discharges. It is interesting to note that the helium perturbation arrived in the interior of the plasma before the electron density perturbation. Because of the constraints of ambipolarity, this is only possible if the background plasma ions (deuterium ions or fully-stripped carbon) responded to the presence of the perturbation. The diffusivities $D_{e}^{p} \equiv-\partial \Gamma_{d} / \partial n_{e}$ and $D_{H e}$ are shown in fig. $10(b, c)$. While $D_{\mathrm{He}}$ and $D_{e}^{p}$ are similar in the Supershot, $D_{\mathrm{He}}>\mathrm{D}_{e}^{\mathrm{p}}$ in the L-Mode. As the case of helium and iron in the L-Mode, this demonstrates that using transport measurements of one species as a descriptor of particle transport in general can be misleading.

Also, the equilibrium and perturbed electron diffusivities for the electrons for both $\mathrm{L}$ mode and Supershot are not necessarily the same. Figure 11 shows the electron particle diffusivity $D_{e}^{p}$ (from the helium gas puff) and the effective electron diffusivity $D_{e}^{\text {eff }}$ (from particle "ralance). In the inner half of the plasma, the two quantities are very similar in the L-Mole, but are very different in the Supershot. A possible explanation is that the density and/or gradient dependence of the bulk electron transport machanisms has changed between the two regimes. Such a result can be understood qualitatively from considerations based on transport driven by drift-wave instabilities. As discussed earlier and further in Appendix $B, D_{e}^{p}$ represents the derivative $-\partial \Gamma \partial \partial \nabla n_{e}$ of the flux, evaluated at equilibrium. Simplified forms of drift-wave type theory generally predict that the electron flux is related to the electuon density gradient as $\Gamma_{\bar{e}}=A \nabla n_{c} \beta$, in which case $D_{c}^{e f f}=-A \nabla n_{e} \beta-1$. The 
diffusivity of the electron perturbation is $D_{e}^{p}=-\beta A \nabla n_{c} \beta-1$ or $D_{e}^{p}=\beta D_{c}$ eff. In the $L$ Mode, the ion temperature gradient drive is expected to be dominant because the density profiles are broad and $T_{i} / T_{e}$ is near unity. ${ }^{23}$ In this situation, the dependence of $\Gamma_{e}$ on $\nabla n_{c}$ is not expected to be strongly nonlinear. In the Supershot, the ion temperature gradient drive is expected to be weakened because of the reduced value of $\eta_{i} \equiv d\left(\log T_{i}\right) / d\left(\log n_{i}\right)$ and the increased ratio of $T_{i} / T_{e}$. As a result, both $\eta_{i}$ and trapped electron effects are expected to be important, and the dependence of $\Gamma_{e}$ on $\nabla n_{e}$ is expected to be stronger, i.e. $\beta$ is expected to be larger in the Supershot than in the L-Mode. The qualitative nature of the differences observed between the L-Mode and Supershot are at least consistent with this simplified picture. However, other explanations, such as the presence or absence of an anomalous particle pinch not included in the steady-state particle balance analysis, may also be consistent with the observed differences.

\section{PREDICTIONS FROM QUASILINEAR THEORY AND COMPARISONS WITH MEASUREMENTS}

A comprehensive numerical model ${ }^{14}$ for calculating eigenmodes and eigenfrequencies of electrostatic and electromagnetic modes in a toroidal geometry has been developed and is applied to the present transport studies. While fluctuation saturation levels are unknown, estimates of ratios of transport coefficients and fluxes, e.g. $D_{\mathrm{He}} / D_{\mathrm{Fe}}, D_{\mathrm{He}} / \chi_{\mathrm{Lot}}^{\mathrm{eff}}, \mathrm{V}_{\mathrm{He}} / \mathrm{D}_{\mathrm{He}}$, etc. are obtained. In the context of this quasilinear model, the saturation levels are multiplicative factors common to each predicted flux and cancel when ratios are taken. For input data, plasma profiles of $n_{e}, T_{e}, T_{i}$, and $Z_{e f f}(r)$ are used. The thermal deuteron density $n_{d}$, local q, the plasma beta, and the local beam ion density and energy have been calculated by TRANSP. Results are based on calculations for the fastest growing mode found. These calculations confirm in detail the expectations mentioned in Section II.C.3 and discussed in Ref. 23 regarding the relative roles of $\eta_{i}$ and trapped electron effects in the two plasmas, i.e. for the L-Mode, primarily $\eta_{\mathrm{i}}$ effects are expected, and in the peaked density Supershot, drift wave microinstabilities caused by both $\eta_{i}$ and trapped electron dynamics drive particle and energy transport.

Table I shows ratios of transport coefficients and fluxes as calculated by the quasilinear theory for $\mathrm{r} / \mathrm{a}=0.2$ and 0.5 . Also shown are experimental values for the same ratios. Experimental values were interpolated between values measured at nearby radii where necessary. Experimental uncertainties are shown in parentheses. For the L-Mode case at 
$r / a=0.5$, uncerainties in the theory calculations due to experimental errors in the determination of the gradient of $T_{e}, n_{e}$, and $T_{i}$ are shown as well and are discussed below. These two radii were chosen for the theory calculations because the gradients and values of the bulk plasma quantities are well known there. These two radii are also characterized by very different gradients in the helium and carbon profile shapes in the Supershot. Finally, the measured changes in transport between Supershot and L-Mode occur inside of $\mathrm{r} / \mathrm{a}=$ 0.5: measurements of transport in the inner region show reductions in $D_{H e}, D_{e}^{\text {eff }}$, and $\chi_{i}^{\text {eff }}$.

In the abserice of particle sources, the steady-state helium profile shapes are determined entirely by $\mathrm{V}_{\mathrm{He}} / \mathrm{D}_{\mathrm{He}}$. The calculations of $\mathrm{V}_{\mathrm{He}} / \mathrm{D}_{\mathrm{He}}$ show that the two very different Supershot and L-Mode $\mathrm{He}^{2+}$ profile shapes are consistent with quasilinear theory of drift wave-driven transport. For both plasmas, the measured helium transport is a linear function of the gradient alone at $r / a=0.5$, corresponding to small values of $V_{\mathrm{He}} / \mathrm{D}_{\mathrm{He}}$. This is also true for the $\mathrm{L}$-Mode at $\mathrm{r} / \mathrm{a}=0.2$. This diffusion dominance is in fact predicted by the theory for these three points. For the Supershot, however, the inner minor radius is unique: the measured absolute value of $\mathrm{V}_{\mathrm{He}} / \mathrm{D}_{\mathrm{He}}$ is larger there, implying a small steadystate scale length and strong peaking on axis. Again, this is predicted by the quasilinear theory and manifests itself as a prediction of nonzero inward helium flux in the presence of zero helium density gradient.

The measured ratios $D_{\mathrm{He}} / \mathrm{D}_{\mathrm{Fe}}$ are in reasonable agreement with the predictions. Even though the predicted transport arises from ExB effects, differences in $\mathrm{He}^{2+}$ and $\mathrm{Fe}^{24+}$ transport are expected in some circumstances because of differences in the toroidal transit times of each ion and the finite toroidal extent of the dominant modes. The quasilinear theory predicts the largest difference in $\mathrm{D}_{\mathrm{He}} / \mathrm{DFe}_{\mathrm{Fe}}$ to be found near the center of the L-Mode plasma, which is seen in the measurements. Measurements yield $D_{\mathrm{He}} / \mathrm{D}_{\mathrm{Fe}} \sim 3$ there; the predicted value is about 5 .

It is inferred from power balance analysis that $\mathrm{Q}_{i}>\mathrm{Q}_{\mathrm{e}}$ for all minor radii of these plasmas. While this ordering is anticipated in the quasilinear treatment, the predicted values are often larger than the power balance values. One possible cause of this is that magnetic stochasticity plays some role in heat transport through the electron channel. Alternatively, the collision operator employed in the quasilinear treatment might inadequately describe the power transfer between ions and electrons. Also, these calculations were based on results obtained from examining the fastest growing mode. It is possible that the fastest growing mode is not necessarily that dominates the transport. 
Similarly, the experimentally determined ratio $D_{e}^{c f f} / D_{H e}$ is typically larger than the theoretical value. In this context, however, it is important to examine not cnly the experimental uncertainties but also the effects of the plasma profile uncertainties on the theory calculations themselves. For the L-Mode at $r / a=0.5$, a sensitivity study of the theory results was performed. Gradients in $n_{e}, T_{e}$, and $T_{i}$ were varied within their experimental uncertainties. TRANSP calculations of $n_{d}, q$, plasma beta, and the local beam ion density and energy were repeated with the varied profiles. Ratios of fluxes were then calculated again wilh the quasilinear treatment after finding the fastest growing mode. It was found that the total electron particle flux $\Gamma_{\mathrm{e}}$ is very sensitive to the input data. In fact, it is possible to change the sign of the calculated $\Gamma_{e}$ (and thus $D_{e}^{e f f}$ ) with variations in the gradient of either $n_{e}, T_{e}$, or $T_{i}$. It is not clear whether or not a fully nonlinear theoretical treatment would exhibit this degree of sensitivity. Still, even with the uncertainties in the theory result, the calculations are consistent with experiment in that $\mathrm{D}_{\mathrm{He}}$ and $\mathrm{D}_{\mathrm{Fe}}$ are predicted to be larger than $\mathrm{D}_{\mathrm{e}}^{\text {eff }}$. The resultant uncertainty in the predicted heat fluxes is somewhat less. Here, heat fluxes are always expected to be outward, and errors in $Q_{j} / Q_{e}$ are estimated to be about $50 \%$. Finally, the ratios of trace impurity transport coefficients are the least sensitive quantities studied. Both $\mathrm{V}_{\mathrm{He}} / \mathrm{D}_{\mathrm{He}}$ and $\mathrm{D}_{\mathrm{He}} / \mathrm{D}_{\mathrm{Fe}}$ exhibit about a $15 \%$ uncertainty in this particular case.

\section{CORE TRANSPORT AND HELIUM ASH ACCUMULATION}

The helium ash density in a future fusion reactor depends on the local relationship between core energy transport and thermal helium transport as well as edge helium transport and pumping speed.24,25,26,27,28. Examined here is the role of the measured correlation between $D_{\mathrm{He}}$ and $\chi_{\text {tot }}^{\text {eff }}$ and the importance of core helium peaking of the type rneasured in the Snoershot in determining central helium content in ITER.

In the limit where the heat flux $Q$ is from alpha particle heating alone, the assumption that the slowing-down alpha particles do not diffuse leads to an ash source profile shape that is the same as the heating source profile shape. In steady-state, $-\nabla \cdot \Gamma_{\mathrm{He}}=S_{\mathrm{He}}$, where $S_{\mathrm{He}}$ is the thermal alpha source. The heat source is given by $E_{\alpha} S_{H e}$, where $E_{\alpha}$ is the alpha energy of $3.5 \mathrm{MeV}$, and $-\nabla \cdot \mathrm{Q}=\mathrm{E}_{\alpha} \mathrm{S}_{\mathrm{He}}$. For steady state, relating the two equations of continuity yields 
$\frac{d n_{H e}}{d r}-\frac{V_{H e}}{D_{H c}} n_{H c}=-n_{c} \frac{\chi_{t O l}^{c l f}}{D_{H e} E_{\alpha}} \frac{d T}{d r}$.

Under some circumstances, this expression can be simplified to reveal the importance of the relation between local helium particle and energy transport. If the helium transport is dominated by diffusion and if the electron density profile is flat, then an expression valid for all shapes of $D_{\mathrm{He}}$ and $\chi_{\text {tot }}^{\text {eff }}$ but constant $\chi_{\mathrm{tot}}^{\mathrm{eff}} / \mathrm{D}_{\mathrm{He}}$ is

$$
\frac{n_{H e}(r)}{n_{e}(r)} \cong \frac{\chi_{\text {tot }}^{e f f}(r)}{D_{H e}(r)} \frac{T(r)}{E_{\alpha}}+\frac{n_{H e}(a)}{n_{e}(r)} .
$$

From this relation, it is clear that the relation between energy and helium particle transport is tremendously important. Simple magnetic stochastic considerations yiel$\chi_{\text {tof }}^{\text {eff }} / \mathrm{D}_{\mathrm{He}} \approx \sqrt{\mathrm{m}_{\mathrm{He}} / \mathrm{m}_{\mathrm{e}}}=85$. If $\mathrm{T}(0)=30 \mathrm{keV}, \mathrm{n}_{\mathrm{e}}(0)=1.35 \times 10^{20} \mathrm{~m}^{-3}$, and the edge helium density $n_{\mathrm{He}}(\mathrm{a})=0.1 \mathrm{n}_{\mathrm{e}}(\mathrm{a})$ (required for proper divertor pumping ${ }^{23}$ ), this implies enormous helium concentrations of $70 \%$, clearly incompatible with sustained ignition. However, if $\chi_{\text {tor }}^{\text {eff }} / D_{\mathrm{He}}-1$, typical of the values found here for the Supershot and L-Mode, expected helium concentrations are about $2 \%$.

However, $\mathrm{V}_{\mathrm{He}} \neq 0$ in some plasmas, as was clearly seen for $\mathrm{r} / \mathrm{a}<0.4$ in the Supershot. We investigate the importance of convection in the inner half of a broad electron density profile plasma by solving eq: (8), using plasma profiles similar to those used in Ref. 26 for an ignited ITER plasma $\left(r=3.1 \mathrm{~m}, \mathrm{~T}(0)=30 \mathrm{keV}, \mathrm{n}_{e}(0)=1.35 \times 10^{20}\right.$ $\mathrm{m}^{-3},\left\langle\mathrm{n}_{\mathrm{e}}\right\rangle=1.2 \times 10^{20} \mathrm{~m}^{-3}, Z_{\text {eff }}$ from carbon $\left.=1.4\right)$. An edge helium density of $0.1 \mathrm{n}_{\mathrm{e}}(\mathrm{a})$ was assumed. Here we assume that $\chi_{\text {tor }}^{\text {eff }} / \mathrm{D}_{\mathrm{He}}=3$ throughout the cross section. This larger value is comparatively pessimistic from the point of view of ash accumulation.

Both the Supershot and L-Mode helium and energy transport coefficients lead to helium ash profiles that do not quench the plasma burn. ${ }^{26}$ Results obtained with the nominal LMode and Supershot experimental values of $\mathrm{V}_{\mathrm{He}} / \mathrm{D}_{\mathrm{He}}$ for $\mathrm{r} / \mathrm{a}<0.8$ expressed as a function of $\mathrm{r} / \mathrm{a}$ measured are shown in fig. 12. The L-Mode transport coefficients lead to a predicted helium profile that is quite broad, despite the presence of a centrally peaked thermal alpha source. Central helium concentrations are about $8 \%$, consistent with sustained ignition at these densities and temperatures. Not surprisingly, the profile obtained using the Supershot transport coefficients is very similar to that measured in these experiments. This 
is because at these densities $\left(\mathrm{V}_{\mathrm{Hc}} / \mathrm{D}_{\mathrm{He}}\right) \mathrm{n}_{\mathrm{Hc}}>\mathrm{n}_{\mathrm{e}} \chi_{\text {tol }}^{\mathrm{clf}} / \mathrm{E}_{\alpha} \mathrm{D}_{\mathrm{He}}(\mathrm{dT} / \mathrm{dr})$. From eq. 8, then, $\mathrm{dn}_{\mathrm{He}} / \mathrm{dr}$ is determined by core transport, not the thermal alpha particle profile.' While the helium profiles obtained using the Supershot $\mathrm{V}_{\mathrm{He}} / \mathrm{D}_{\mathrm{He}}$ are strongly peaked, the fusion fuel dilution in this broad electron density plasma occurs in a region of small plasma volume, leading to a relatively small decrease in fusion power of about $10 \%$. Of course, if helium particle convection is important for larger values of $r / a$ than measured here, then the fraction of the plasma volume occupied by helium ash can be more significant.

\section{SUMMARY}

These local measurements reveal important similarities and differences in the transport of low and high $\mathrm{Z}$ impurities, electrons, and energy. Among the similarities, the diffusive transport coefficients measured by perturbations for helium $\left(D_{\mathrm{He}}\right)$, iron $\left(\mathrm{D}_{\mathrm{Fe}}\right)$, and electrons ( $D_{e}^{p} \equiv-\partial \Gamma_{e} \partial \partial n_{e}$ ) and the effective electron diffusivity $D_{e}^{\text {eff }} \equiv-\Gamma_{e} / \nabla n_{e}$ inferred from particle balance analysis are radially hollow in all cases and larger than neoclassical values, except near the magnetic axis.

Particle and energy transport are similar in ordering of the transport coefficients. The measured particle diffusivities $D_{\mathrm{He}}$ and $\mathrm{D}_{\mathrm{Fe}}$ are larger than the steady-state diffusivity of the electrons $D_{e}^{\text {eff }}$ for both the L-Mode and the Supershot. Likewise, the ion thermal conductivity $\chi_{i}^{\text {eff }}$ is larger than the electron thermal conductivity $\chi_{e}^{\text {eff }}$ for both plasmas. The dominance of the ion channels for both particles and energy is predicted by quasilinear theory. Even though predictions of $D_{e}^{\text {eff }}$ are highly sensitive to uncertainties in the input data, the magnitude of $D_{e}^{\text {eff }}$ is smaller than $D_{H e}$ and $D_{F e}$ for all cases studied. Also, while quasilinear theory is in qualitative agreement with experiment in that $\mathrm{Q}_{\mathrm{i}}>\mathrm{Q}_{\mathrm{e}}$ for these plasmas at all radii, $Q_{i} / Q_{e}$ is often predicted to be larger than the experimental value.

Similarities between particles and energy extend to the behavior in the ion channel between confinement regimes. A reduction in $\mathrm{D}_{\mathrm{He}}$ in the Supershot as compared to the $\mathrm{L}$ Mode for $r / a<0.5$ is accompanied by a similar reduction in $\chi_{i}^{\text {eff }}$. Because the ion channel

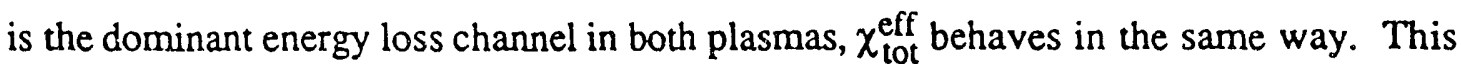
relation between core helium particle transport and energy transport is favorable with respect to the issue of helium ash removal in a tokamak fusion reactor.

Inward convection (larger than neoclassical values) for helium is measured for $\mathrm{r} / \mathrm{a}<0.5$ in the Supershot. This is consistent with predictions from quasilinear drift-wave instability 
theory. A broad helium profile is predicted for $r / a=0.5$ in the Supershot and $r / a=0.2$ and 0.5 in the L-Mode. These predictions are also consistent with the measurements. Core peaking of the helium profile of the type found in the Supershot will increase the on-axis concentration of helium ash in a tokamak fusion reactor. However, if the relations between energy and particle diffusion are similar to those measured here, and if the bulk plasma density profile is broad, then the helium peaking will result in only a modest loss in fusion reactivity.

Different particles from the same gas puff do not necessarily transport alike. In the LMode, the density perturbation of electrons arrives in the center L-mode plasmas after the helium perturbation. The transport coefficients derived from these perturbations reflect these differences. Also, all impurities do not necessarily have the same transport coefficients. While $D_{\mathrm{He}}$ and $D_{\mathrm{Fe}}$ are quite similar in the Supershot, $D_{\mathrm{He}}>\mathrm{D}_{\mathrm{Fe}}$ near the magnetic axis of the L-Mode. With respect to these differences between $D_{\mathrm{He}}$ and $D_{\mathrm{Fe}}$, the quasilinear theory does quite well. Ratios of $D_{\mathrm{He}}$ to $D_{\mathrm{Fe}}$ predicted in the quasilinear framework are found to be within a factor of two of measured values for two different radial locations $(\mathrm{r} / \mathrm{a}=0.2$ and $\mathrm{r} / \mathrm{a}=0.5$ ) in both the L-Mode and Supershot. In particular, it is observed that $D_{\mathrm{He}}$ is clearly larger than $\mathrm{D}_{\mathrm{Fe}}$ at $\mathrm{r} / \mathrm{a}=0.2$ in the L-Mode. This is predicted by the quasilinear theory. These experimental and theoretical results serve as a warning against using a particle transport measurement of one species as a descriptor of particle transport in general.

In the Supershot, the electron diffusivity measured from the perturbation is not the same as the effective diffusvity from particle balance. However, the two quantities are much more similar in the L-Mode. One possible explanation is that trapped electron and $\eta_{i}$ -type dynamics are expected to be present in the Supershot, while $\eta_{i}$ effects are expected to dominate the L-Mode. Trapped electron effects are expected to lead to a stronger nonlinear dependence of the electron particle flux on the electron density gradient than would be observed if only $\eta_{i}$-type effects were present.

Future work includes extending the helium and electron transport studies to L-Mode plasmas of various temperatures and densities in order to study the parametric dependence of the local transport on local quantities such as $n_{e}$ and $T_{e}$. These studies will also be carried out in conjunction with energy transport studies in order to further explore the relation between helium transport and energy transport. Use of the local fluctuation levels as measured by beam emission spectroscopy and reflectometry should allow the 
substitution of measured fluctuation saturation levels into transport calculations in order to obtain estimates of the absolute particle and energy flux levels expected.

\section{ACKNOWLEDGMENTS}

The authors gratefully acknowledge the support of the TFTR staff in the execution of these experiments. R.E. Bell developed a greatly improved error treatment of the CHERS ion temperature data that was particularly useful in determining the uncertainties in the power balance calculations. Discussions with Steve Cowley are appreciated. N. Schechtman provided invaluable computer support for these experiments. R.E. Olson (University of Missouri) supplied calculations of needed iron charge exchange cross sections and made available his Classical Trajectory Monte Carlo code. This enabled us to calculate the cross sections for charge exchange between excited neutral atoms and helium ions. R. Phaneuf (University of Nevada) provided useful guidance pertaining to the relevant atomic physics of helium ion plumes. The work of L. Friedman (currently at the University of Chicago) on neoclassical impurity transport coefficient calculations is most appreciated.

This work was supported by the U.S. Department of Energy, Contract No. DE-AC0276-CHO-3073.

\section{APPENDIX A. CHARGE EXCHANGE RECOMBINATION SPECTROSCOPY OF FULLY STRIPPED HELIUM AND HELIUM-LIKE IRON}

The transport of fully stripped helium and helium-like iron have been explored with the technique of Charge Exchange Recombination Spectroscopy (CHERS). An outline of CHERS measurement techniques is presented here to aid discussion of issues that can complicate interpretation of the data.

CHERS measurements take advantage of the reaction

$D^{0}+A^{Z}->D^{+}+A(Z-1) *$

where $\mathrm{D}^{0}$ is an energetic deuterium beam neutral, and $\mathrm{A}^{\mathrm{Z}}$ is an impurity ion of charge $\mathrm{Z}$. The product impurity ion is usually created in an excited state that rapidly decays to lower- 
lying levels, radiating photons in the process of the cascade. The local impurity density can be inferred from the measured brightness of a charge-exchange-excited spectral line if the local neutral beam density and the rate coefficient for exciting the line are known:

$B=\frac{1}{4 \pi} \sum_{j=1}^{3} \int_{n_{A}}\left\langle\sigma v>_{j} n_{0 j} d l\right.$.

Here, $\mathrm{B}$ is the brightness of the spectral line, $<\sigma v>$ is the line excitation rate coefficient, $\mathrm{n}_{0}$ is the local neutral density, and $\mathrm{n}_{\mathrm{A}}$ is the local impurity density. The integral is along the line of sight, and the sum is over the three energy components of the neutral beam, $E_{0}$, $\mathrm{E}_{0} / 2$, and $\mathrm{E}_{0} / 3$.

For both helium and iron, interpreting the measured signals requires knowledge of charge exchange reaction rates as well as beam attenuation. For helium, electron impact excitation rates are also required, as discussed below. Since the transport coefficients for both helium and iron can be deduced from profile shapes rather than from the absolute amplitude of the the profiles, the absolute valies of the of the rates are unimportant. In general, their energy dependence must be known, but since the beam currents on TFTR are dominated by contributions from the full energy component, determining profile shapes is insensitive to uncertainties in the rates.

Measured cross sections from Hoekstra ${ }^{29}$ and Frieling 30 for excitation of the $4686 \AA$ line of $\mathrm{He}^{+}$were used for the full (45 - $\left.50 \mathrm{keV} / \mathrm{amu}\right)$, half $(22.5-25 \mathrm{keV} / \mathrm{amu})$, and onethird (15-17 keV/amu) energy beam components. The reaction-rate coefficient for exciting this transition by charge exchange from the $n=2$ level of deuterium beam neutrals, most important for the one-third energy component of the beam, ${ }^{31}$ has been estimated using the Classical Trajectory Monte Carlo Code (CTMC) code of Olson. The population of the $n=2$ state of the beam neutrals relative to that of the ground state was calculated using the multistep mean-free path treatment of Boley, Janev, and Post. 32 Near the plasma edge, the one-third energy component is not significantly attenuated. This process increases the total $\mathrm{He}^{+}$line emission reaction rate by at most $15 \%$ there. The effect has been included in these measurements.

The energy dependence of the cross-sections for iron was taken from cross-sections for capture into the $n=19$ levels of $\mathrm{Fe}^{24+}$ calculated by Olson ${ }^{33}$ using the CTMC method. 
This approximation is not reliable below $25 \mathrm{keV} / \mathrm{amu}$. For beam energies below this, the cross-section was obtained by extrapolation from higher energies. Because the contribution to the line brightness from the third energy component is small, uncertainty in this extrapolation does not significantly affect the accuracy of the deduced $\mathrm{Fe}^{24+}$ profiles. Multigeneration halo atoms produced by charge exchange between beam neutrals and working plasma ions can contribute to the total brightness of a charge-exchange induced spectral line in high temperature plasm...34 The effect has been estimated for these visible helium and iron lines and is expected to contribute less than $10 \%$ to the total signal and has therefore been neglected.

The impurity ions that undergo charge exchange have ionization mean free paths in the plasma that can extend up to and beyond a large fraction of the torus circumference. This is referred to as the ion plume effect. ${ }^{12}$ Subsequent electron impact excitation of these product ions can potentially enhance the measured signal over that expected by charge exchange alone, and delocalize the measured signal from that expected in the ideal chargeexchange-only situation, especially for low- $Z$ ions. The total brightness of this portion of the signal is a strong function of viewing geometry and plasma conditions.

Plume effects been addressed with a time-dependent code that models the total brightness of the expected signal, including charge exchange and electron impact excitation effects. In the code, trial $\mathrm{He}^{2+}$ profile shapes are iterated until agreement between predicted and observed total line ' ightnesses is achieved. Because of the geometry of these experiments, the plume emission is expected to come predominantly from the major radius of the sightline-neutral beam region. As a result, the time histories of the helium emission are not significantly affected by the plume. Recent measurements of the plume-to-prompt signal intensity ratio and spectral line shape modelling for both helium and carbon emission are in good agreement with model predictions. ${ }^{35}$

\section{APPENDIX B. INTERPRETATION OF TRACE AND BULK PARTICLE FLUXES FOLLOWING PERTURBATIONS}

Developments in the techniques of local perturbative transport studies and discussion regarding their interpretation make it appropriate to examine issues relevant to the determination and interpretation of particle fluxes. Here, a discussion pertaining to the 
differences of interpretation of the results quoted for trace particies (helium and iron) and bulk particles (electrons) is given.

For both impurity and electron transport experiments, the particle flux of a particular species is often assumed to be governed by diffusive and convective processes, i.e.

$\Gamma(\mathrm{r}, \mathrm{t})=-\mathrm{D}(\mathrm{r}) \nabla \mathrm{n}(\mathrm{r}, \mathrm{t})+\mathrm{V}(\mathrm{r}) \mathrm{n}(\mathrm{r}, \mathrm{t})$

where $\mathrm{D}$ and $\mathrm{V}$ are constant over the time of the perturbation. If a linear analysis is performed on the total flux, and if the change in the flux is assumed to be a function of changes in the perturbed quantity and its gradient, the perturbed flux can be expressed in a Taylor expansion as

$$
\begin{aligned}
\delta \Gamma & =(\partial \Gamma / \partial \nabla n) \delta \nabla n+(\partial \Gamma / \partial n) \delta n \\
& =[-\langle D>-(\partial D / \partial \nabla n)<\nabla n>+(\partial V / \partial \nabla n)<n>] \delta \nabla n \\
& +[<V>+(\partial V / \partial n)<n>-(\partial D / \partial n)<\nabla n>] \delta n,
\end{aligned}
$$

where $<>$ denotes steady-state values and $\delta$ refers to perturbed quantities. The derivatives are evaluated at equilibrium. In the trace impurity limit, the transport mechanisms do not depend on the presence of the trace impurity itself, implying that the partial derivatives are zero. In addition, the equilibrium terms vanish for a trace impurity. The perturbed impurity flux then obeys the same transport equation that applies in equilibrium, i.e.

$\Gamma_{z}(r, t)=-\left\langle D_{Z}(r)>\nabla n_{z}(r, t)+<V_{z}(r)>n_{z}(r, t)\right.$

where $D_{Z}$ and $V_{Z}$ are determined entirely by background plasma quantities. In this light, the helium and iron transport results presented here are interpreted as steady-state values.

The issue becomes more subtle when the transport of a bulk plasma species such as electrons is in question. It has been pointed out that the perturbed flux of bulk particles may obey a transport equation very different from that applicable to steady-state, even in the limit of an infinitesimally small puff. 1,36,37 For a perturbation of a bulk plasma quantity, a small change in the background transport coefficients from an arbitrarily small perturbation can result in a contribution to the total change in the particle flux, $\delta \Gamma$, from the background particles that is on the order of that due to the transport of the externally applied 
perturbation itself. For an electron density perturbation, the steady-state terms in the brackets are not zero, implying that their product with the partial deivatives in eq. 8 are not ignorable. The transport coefficients $D_{e}^{p}=-\partial \Gamma_{e} \partial \nabla n_{e}$ and $V_{e}^{p}=\partial \Gamma_{e} \partial n_{e}$ of the perturbation of the electrons are then to be viewed as the diffusivity and convection of the perturbation. They are related to, but may not be equivalent to, steady-state values. This has powerful implications: knowledge of the steady-state transport obtained from partisle balance and the perturbation transport coefficients obtained from gas puffing can provicle coristraints on the density and gradient dependence of the underlying transport mechanisms. ${ }^{38}$ The different interpretations of $\mathrm{D}_{\mathrm{e}}^{\text {eff }}$ and $\mathrm{D}_{\mathrm{e}}^{\mathrm{p}}$ has been underscored in this work and may relate to the similarities and differences between the two quantities, as is discussed in Section II.C.3.

1 P.C. Efthimion, D.K. Mansfield, B.C. Stratton, E. Synakowski, A. Bhattacharjee, H. Biglari, P.H. Diamond, R.J. Goldston, C.C. Hegna, D. McCune, G. Rewoldt, S. Scott, W.M. Tang, G. Taylor, R.E. Waltz, R.M. Wieland, and M.C. Zamstorff, Phys. Rev. Lett. 66 (1991) 421.

2 E.J. Synakowski, B.C. Stratton, P.C. Efthimion, R.J. Fonck, R.A. Hulse, D.W. Johnson, D.K. Mansfield, H. Park, S.D. Scou, and G. Taylor, Phys. Rev. Lett. 65 (1990) 2255.

3 R.J. Fonck and R.A. Hulse, Phys. Rev. Lett. 52 (1984) 530.

4 E.J. Synakowski, R.D. Bengtson, , A. Ouroua, A.J. Wootton, S.K. Kim, Nucl. Fusion 29 (1989) 311.

5 B.C. Stratton, E.J. Synakowski, P.C. Efthimion, R.J. Fonck, K.W. Hill, R.A. Hulse, D.W. Johnson, H. Park, G. Taylor, J. Timberlake, Nucl. Fusion 31 (1991) 171.

6 R.J. Groebner, W. Pfeiffer, F.PI Blau, K.H. Burrell, E.S. Fairbanks, R.P. Seraydarian, H. St. John, and R.E. Stockdale, Nucl. Fusion 26 (1986) 543.

7 R.J. Fonck, R. Howell, K. Jaehnig, L. Roquemore, G. Schilling, S. Scoth, M.C. Zarnstorff, C. Bush, R. Goldston, H. Hsuan, D. Johnson, A. Ramsey, J. Schivell, and H. Towner, Phys. Rev. Lett. 63, (1989) 520.

8 S. Scoth, P. Diamond, R. Fonck, R. Goldston, R. Howell, K. Jaehnig, G. Schilling, E. Synakowski, M. Zarnstorff, C. Bush, E. Fredrickson, K. Hill, A. Janos, D. Mansfield, D. Owens, H. Park, G. Pautasso, A. Ramsey, J. Schivell, G. Tait, W. Tang, and G. Taylor, Phys. Rev. Lett. 64 (1990) 531.

9 M.L. Watkins, B. Balet, V.P. Bhatnager, J.G. Cordey, G.W. Hammett, T. Hellsten, M. Keilhacker, S.L. Milora, P. D. Morgan, C. Sack, G.L. Schmidt, A. Taroni, P.R. Thomas, K. Thomsen, F. Tibone, M. von Hellermann, H. Weisen, Plasma Phys. and 'Jontr. Fusion 31 (1987) 1713.

10 J.D. Strachan, M. Bitter, A.T. Ramsey, M.C. Zamstroff, V. Arunasalam, M.G. Bell, N.L. Bretz, R. Budny, C.E. Bush, S.L. Davis, H.F. Dylla, P.C. Efthimion, R.J. Fonck, E. Fredrickson, H.P. Furth, RJ. Goldston, L.R. Grisham, B. Grek, R.J. Hawryluk, W.W. Heidbrink, H.W. Hendel, K.W. Hill, H. Hsuan, K.P. Jaehnig, D.L. Jassby, F. Jobes, D.W. Johnson, L.C. Johnson, R. Kaita, J. Kamperschroer, RJ. Knize, T. Kozub, H. Kugel, B. LeBlanc, F. Levinton, P.H. LaMarche, D.M. Manos, D.K. Mansfield, K. McGuire, D.H. McNeill, D.M. Meade, S.S. Medely, W. Morris, D. Mueller, E.B. Nieschmidt, D.K. Owens, H. Park, J. Schivell, G. Schilling, G.L. Schmidt, S.D. 
Scott, S. Sesnic, J.C. Sinnis, FJ. Stauffer, B.C. Stratton, G.D. Tait, G. Taylor, H.H. Towner, M. Ulrickson, S. von Goeler, R. Wieland, M.D. Williams, K.-L. Wong, S. Yoshikawa, K.M. Young, and S.J. Zweben, Phys. Rev. Lett. 58 (1987) 1004.

11 R.C. Isler and L.E. Murray, Appl. Phys. Lett. 42, 355 (1983).

12 R.J. Fonck, D.S. Darrow, K.P. Jaehnig, Phys. Rev. A 29 (1984) 3288.

13 D.K. Mansfield, H.K. Park, L.C. Johnson, H.M. Anderson, R. Chouinard, V.S. Foote, C.H. Ma, and B.J. Clifton, Appl. Optics 26 (1987) 4469.

14 G. Rewoldt, W.M. Tang, R.J. Hastie, Phys. Fluids 30 (1987) 807.

15 B.C. Stratton, R.J. Fonck, K.P. Jaehnig, N. Schechtman, and E.J. Synakowski, in Proceedings of the IAEA Technical Committee Meeting on Time Resolved Two- and Three-Dimensional Plasma Diagnostics (1991) 78.

16 R.A. Hulse, Nucl. Technol. Fusion 3 (1983) 259.

17 P.C. Efthimion, M. Bitter, E.D. Fredrickson, R.J. Goldston, G.W. Hammett, K.W. Hill, H. Hsuan, R.A. Hulse, R. Kaita, D.K. Mansfield, D.C. McCune, K.M. McGuire, S.S. Medley, D. Mueller, A.T. Ramsey, S.D. Scott, B.C. Stratton, K.-L.Wong, H. Biglari, P.H. Diamond, Y.Takase, V.A. Vershkov, in Plasma Physics and Controlled Nuclear Fusion Research 1988 (IAEA, Vienna, 1989), $1,307$.

18 J. Timberlake, S. Cohen, C. Daughney, and D. Manos, J. Vac. Sci. Technol. A (1983) 841.

19 R.J. Hawryluk, in Physics Close to Thermonuclear Conditions (Proc. Course Varenna, 1979), Commission of the European Communities, Brussels (1979).

20 M.C. Zarnstorff, V, Arunasalam, C.W. Barnes, M.G. Bell, M. Bitter, H.-S. Bosch, N.L. Bretz, R. Budny, C.E. Bush, A. Cavallo, T.K. Chu, S.A. Cohen, P.L. Colestock, S.L. Davis, D.L. Dimock, H.F. Dylla, P.C. Efthimion, A.B. Ehrhardt, RJ. Fonck, E.D. Fredrickson, H.P. Furth, G. Gammel, R.J. Goldston, G.J. Greene, B. Grek, L.R. Grisham, G.W. Hammett, R.J. Hawryluk, H.W. Hendel, K.W. Hill, E. Hinnov, J.C. Hosea, R.B. Howell, H. Hsuan, R.A. Hulse, K.P. Jaehnig, A.C. Janos, D.L. Jassby, F.C. Jobes, D.W. Johnson, L.C. Johnson, R. Kaita, C. Kieras-Phillips, S.J. Kilpatrick, V.A. Krupin, P.H. LaMarche, B. LeBlanc, R. Little, A.I. Lysojvan, D.M. Manos, D.K. Mansfield, E. Mazzucato, R.T. McCann, M.P. McCarthy, D.C. McCune, K.M. McGuire, D.H. McNeill, D.M. Meade, S.S. Medley, D.R. Mikkelsen, R.W. Motley, D. Mueller, Y. Murakami, J.A. Murphy, E.B. Nieschmidt, D.K. Owens, H.K. Park, A.T. Ramsey, M.H. Redi, A.L. Roquemore, P.H. Rutherford, T. Saitn, N.R. Sauthoff, G. Schilling, J. Schivell, G.L. Schmidt, S.D. Scott, J.C. Sinnis, J.E. Stevens, W. Stodiek, J.D. Strachan, B.C. Stratton, G.D. Tait, G. Taylor, J.R. Timberlake, H.H. Towner, M. Ulrickson, S. von Goeler, R.M. Wieland, M.D. Williams, J.R. Wilson, K.-L. Wong, S. Yoshikawa, K.M. Young, and S.J. Zweben, Plasma Physics and Controlled Nuclear Fusion Research 1988 (IAEA, Vienna, 1989), 1, 183.

21 F.H. Seguin, R. Petrasso, E.S. Marmar, Phys. Rev. Lett. 51 (1983) 455.

22 K.W. Wenzel, D.J. Sigmar, Nucl. Fus. 30 (1990) 1117.

23 G. Rewoldt and W.M. Tang, Phys. Fluids B 2 (1990) 318.

24 F. Engelmann, A. Nocentine, Comments Plasma Phys. Controlled Fusion 5 (1980) 253

25 R.J. Taylor, B.D. Fried, G.J. Morales, Comments Plasma Phys. Controlled Fusion 13 (1990) 227.

26 M.H. Redi, S.A. Cohen, E.J. Synakowski, Nucl. Fusion 31 (1991) 1689.

27 D.L. Hillis, K.H. Finken, J.T. Hogan, K.H. Dippel, R.A. Moyer, A. Pospieszczyk, D. Rusbuldt, K. Akaishi, R.W. Conn, H. Euringer, D.S. Gray, L.D. Horton, R.A. Hulse, R.C. Isler, C.C. Klepper, P.K. Mioduszewski, A. Miyahara, and G.H. Wolf, Phys. Rev. Lett. 65 (1990) 2382.

28 D. Reiter, H. Kever, G.H. Wolf, M. Baelmans, R. Behrish, R. Schneider, Plasma Phys. Controlled Fusion 33 (1991) 1579. 
29 R. Hoekstra, F.J. de Heer, R. Morgenstern, J. Phys. B. 24 (1991) 4025.

30 G.J., Frieling, R. Hoekstra, E. Smulders, W. Dickson, A.N. Zinoviev, S.J. Kuppens, and FJ. de Heer, J. Phys. B. 25 (1992) 1245.

31 R.C. Isler and R.E. Olson, Phys. Rev. A 37, No. 9 (1988) 3399.

32 C.D. Boley, R.K. Janev, D.E. Post, Phys. Rev. Lett. 52 (1984) 534.

33 R.E. Olson, private communication

34 B.C. Stratton, R.J. Fonck, A.T. Ramsey, E.J. Synakowski, B. Grek, K.W. Hill, D.W. Johnson, D.K. Mansfield, H. Park, and G. Taylor, Nucl. Fusion 30 (1990) 675.

35 EJ. Synakowski, R.E. Bell, D.W. Johnson, E.C. Stratton, in Proceedings of the 9th Topical Conference on High Temperature Plasma Diagnostics, March 1992, Rev. Sci. Instr. 63, No. 10, PL II (1992) 5195.

36 M. Hossain, M. Kress, P.N. Hu, A.A. Blank, and Harold Grad, Phys. rev. Lett. 58 (1987) 487.

37 K.W. Genule, Phys. Fluids 31 (1988) 1105.

38 K.W. Gentle, B. Richards, M.E. Austin, R.V. Bravenec, D.L. Brower, R.F. Gandy, W.L. Li, P.E. Phillips, D.W. Ross, W.L. Rowan, P.M. Schoch, P.M. Valanju, and A.J. Wootton, Phys. Rev. Lett. 68 (1992) 2444. 


|




\section{Figure Captions}

Figure 1. Plasma profiles, mapped to minor radius, for the L-Mode and Supershot. Measurements were made just prior to the helium gas puff. (a). Electron density $n_{e}$ (b). Electron temperature $T_{e}$ and ion temperature $T_{i}$.

Figure 2. Line-integrated electron density during the neutral-beam heated phase of a Supershot with a helium gas puff at $3.58 \mathrm{~s}$. The shaded region represents the perturbation to the puff.

Figure 3. Schematic of CHERS system, sightlines, and neutral beams used for these experiments.

Figure 4. The normalized flux $\Gamma_{\mathrm{He}} / \mathrm{n}_{\mathrm{He}}$ vs. $\nabla n_{\mathrm{He}} / \mathrm{n}_{\mathrm{He}}$ for the L-Mode at a point near the plasma half radius.

Figure 5. Steady-state $\mathrm{He}^{2+}$ density profiles and the helium concentration $\mathrm{He}^{2+/ \mathrm{n}_{\mathrm{e}}}$ (in arbitrary units) for the Supershot and L-Mode. The shaded regions represent experimental uncertainties. They are largely systematic and are dominated by uncertainties in the neutral beam stopping cross section and the plume emission correction.

Figure 6. Paricle transport coefficients for the Supershot and L-Mode. (a). The helium diffusivity $D_{\mathrm{He}}$ (b). The iron diffusivity $D_{\mathrm{Fe}}$. (c). The effective electron diffusivity $D_{e}^{\text {eff }}$.

Figure 7. Thermal transport coefficients for the Supershot and L-Mode. (a). The effective ion thermal conductivity $\chi_{i}^{\text {eff }}$ (b). The effective electron thermal conductivity $\chi_{e}^{\text {eff }}$. (c). The average effective thermal conductivity $\chi_{\text {tot }}^{\text {eff }}$.

Figure 8. Helium convective velocity profiles for the (a). Supershot and (b). L-Mode. Local measurements and neoclassical values are shown. The experimental uncertainties (shaded regions) are predominantly systematic.

Figure 9. Iron convective velocity profiles for the Supershot and L-Mode. Values have been parameterized since the total iron profile is not known.

Figure 10. (a) Perturbed density change for $\mathrm{He}^{2+}$ and electrons following a helium gas puff for the $L$-Mode at $r / a=0.4$. The data is an averaged ensemlble from the same set of 
L-Mode plasmas. (b). The helium diffusivity $\mathrm{D}_{\mathrm{He}}$ and the perturbative electron diffusivity $\mathrm{D}_{\mathrm{e}}^{\mathrm{P}}$ for the L-Mode. (c). Same as (b), but for the Supershot.

Figure 11. Electron diffusivity $D_{e}^{p}$, inferred from the perturbation, and $D_{e}^{e f f}$, inferred from particle balance, for the (a). Supershot and (b). L-Mode.

Figure 12. Predicted steady-state helium profiles for ITER obtained with the helium transport coefficients measured in the Supershot and L-Mode and $\chi_{\text {tot }}^{\text {eff }} / D_{\mathrm{He}}=3$. Also shown is the electron density profile (divided by 4 ) assumed for the calculation. The plasma profiles used for the calculations are similar to those used in Ref. 21, for which time-dependent simulations yield sustained ignition. 

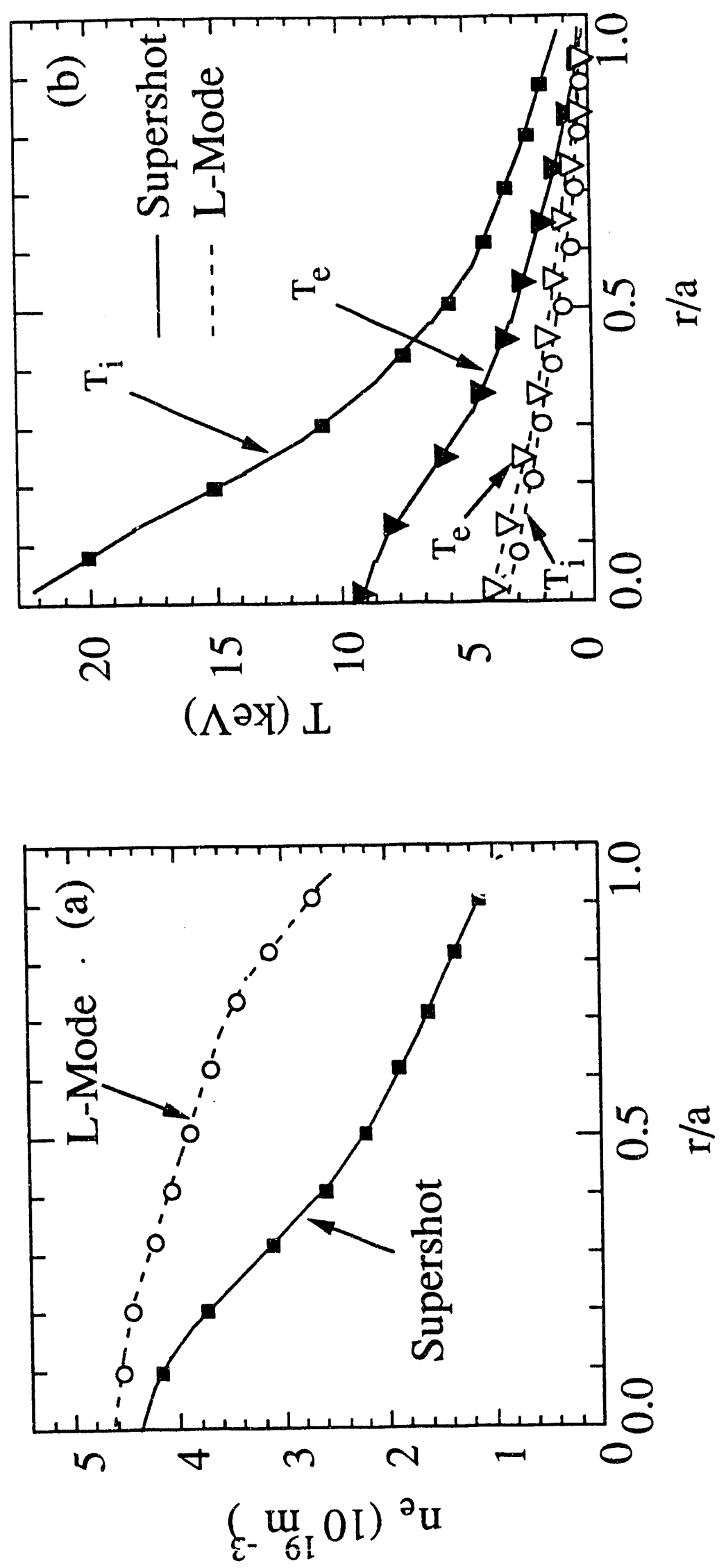


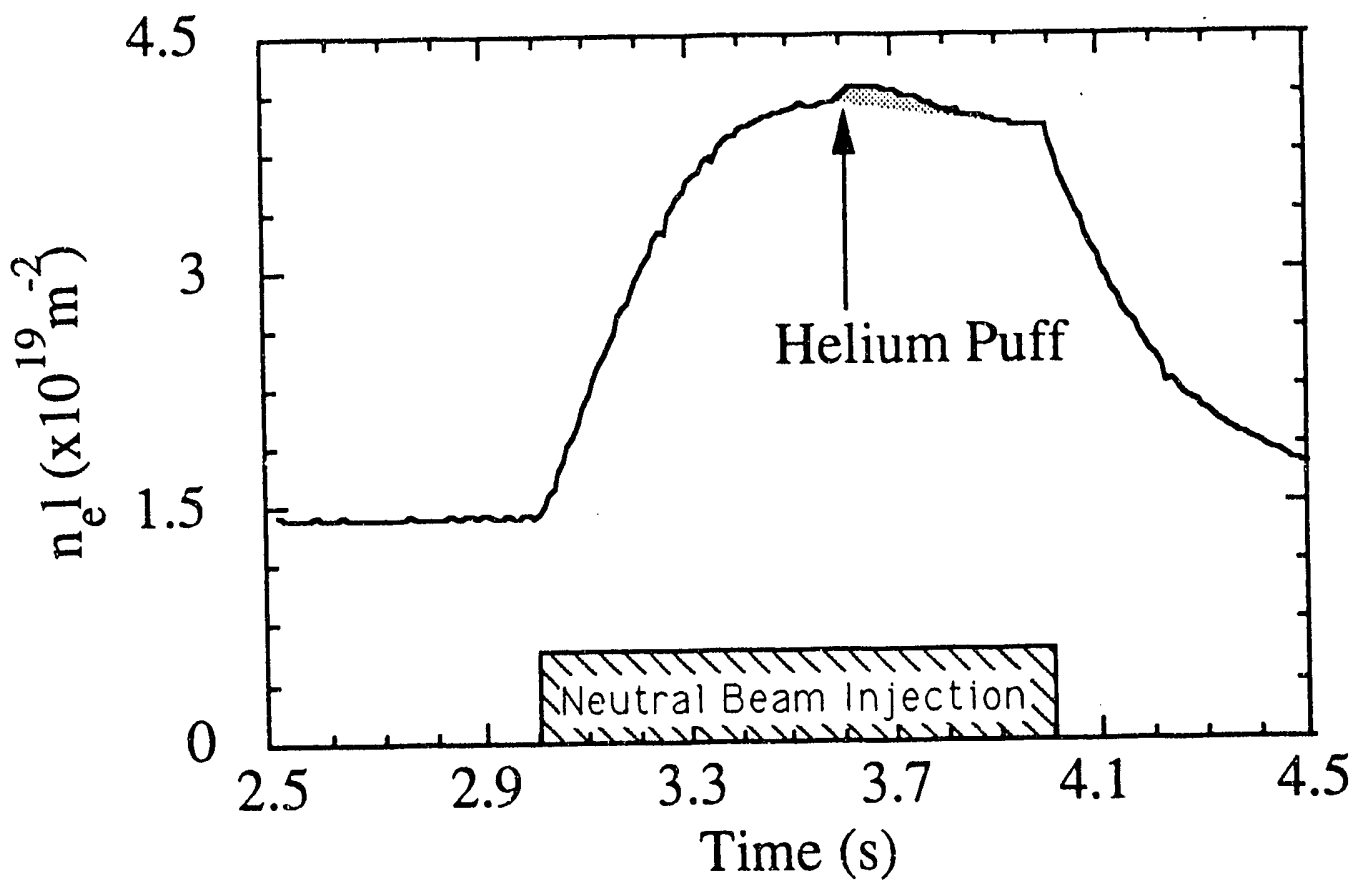

Fig. 2 


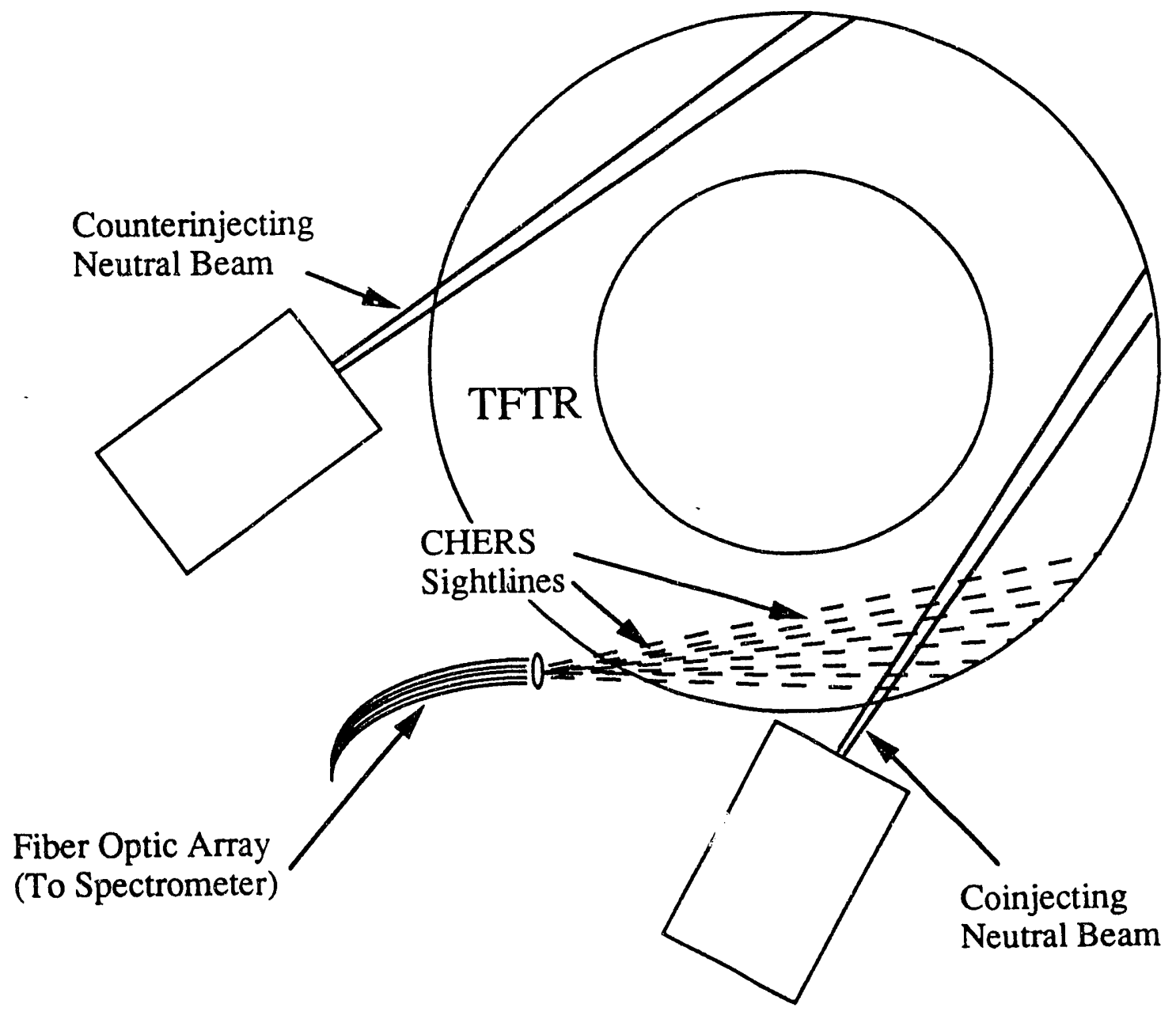

Fig。 3 


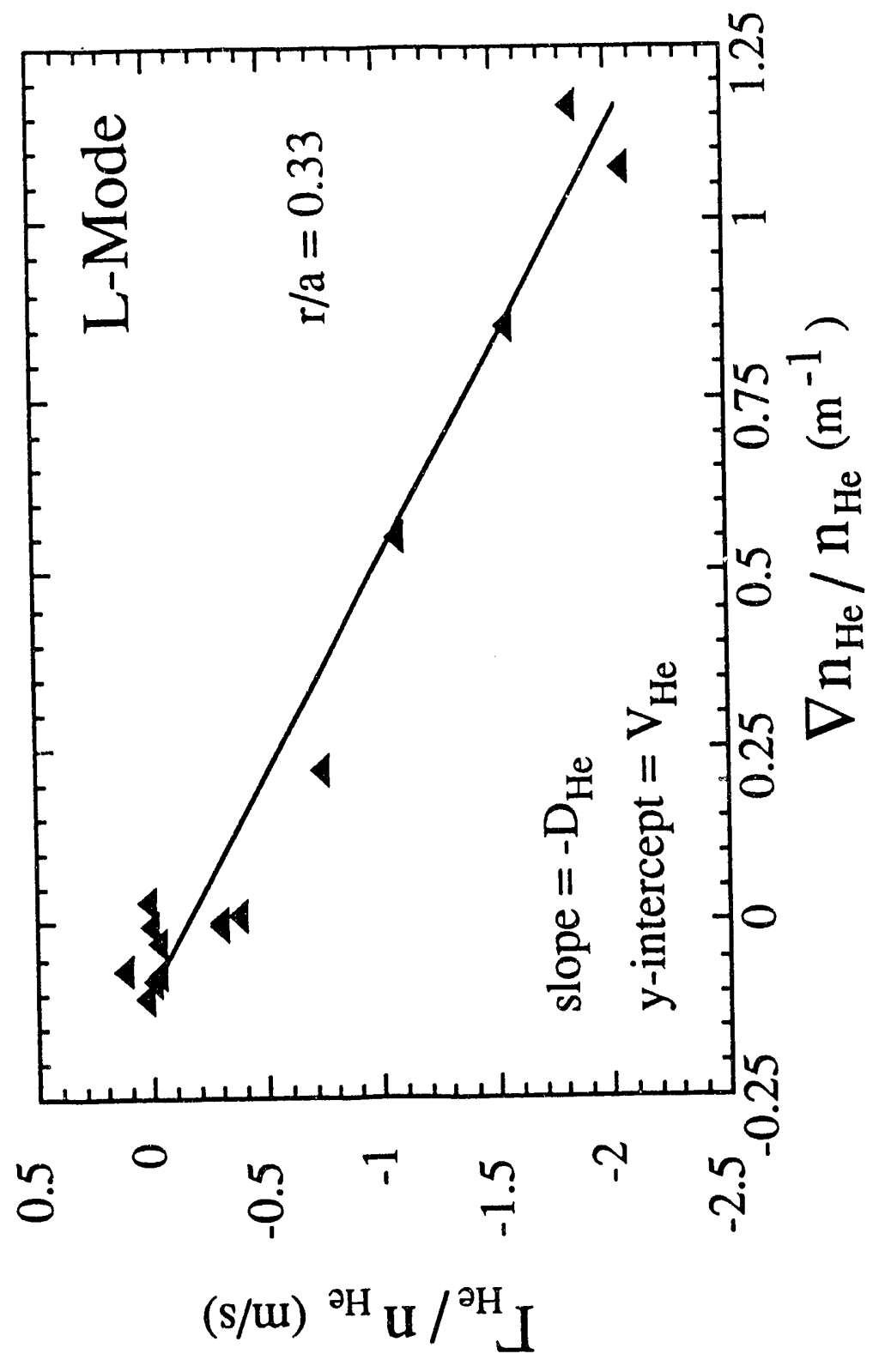

$\underset{\dot{D}}{\dot{a}}$ 

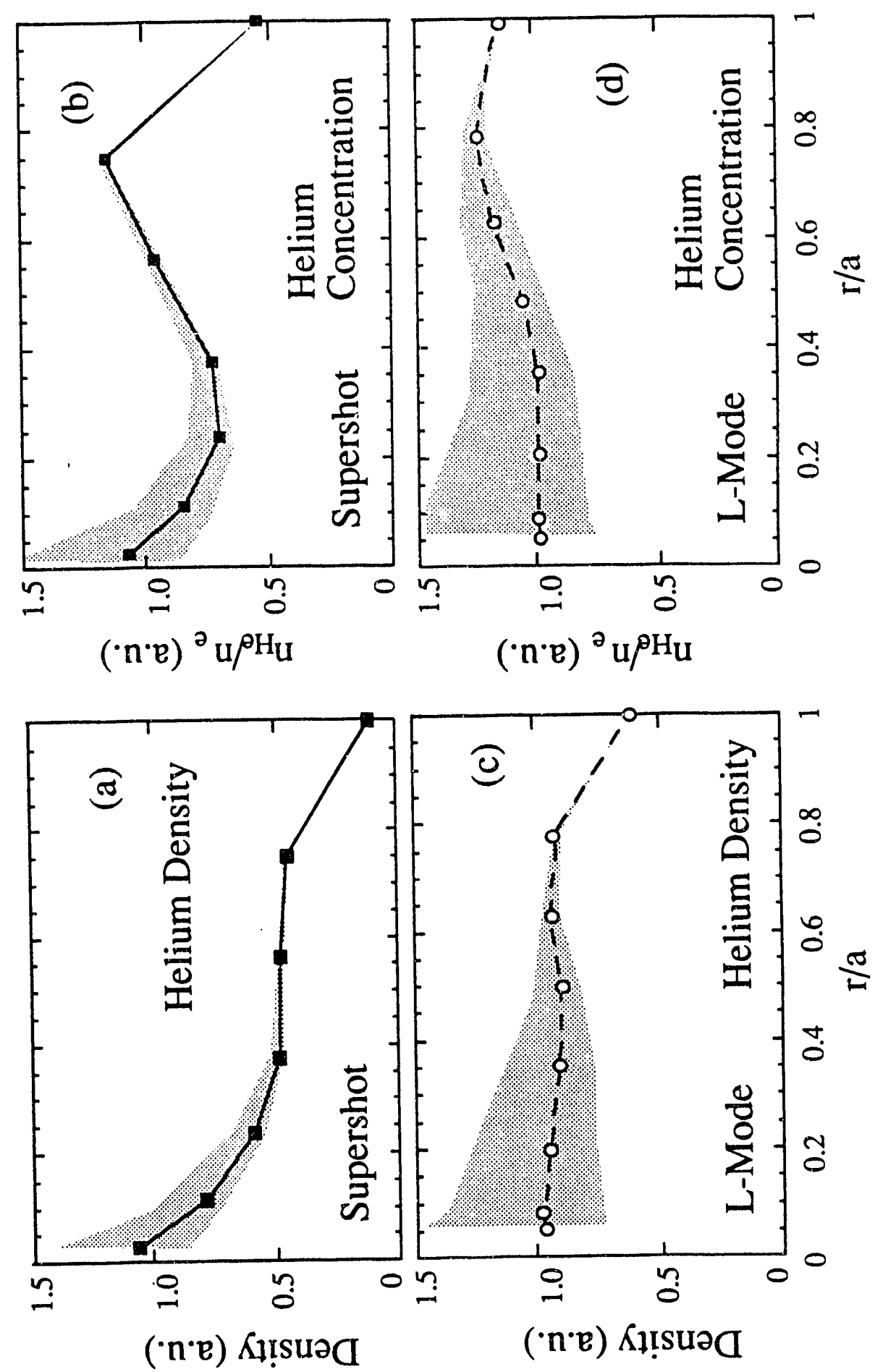

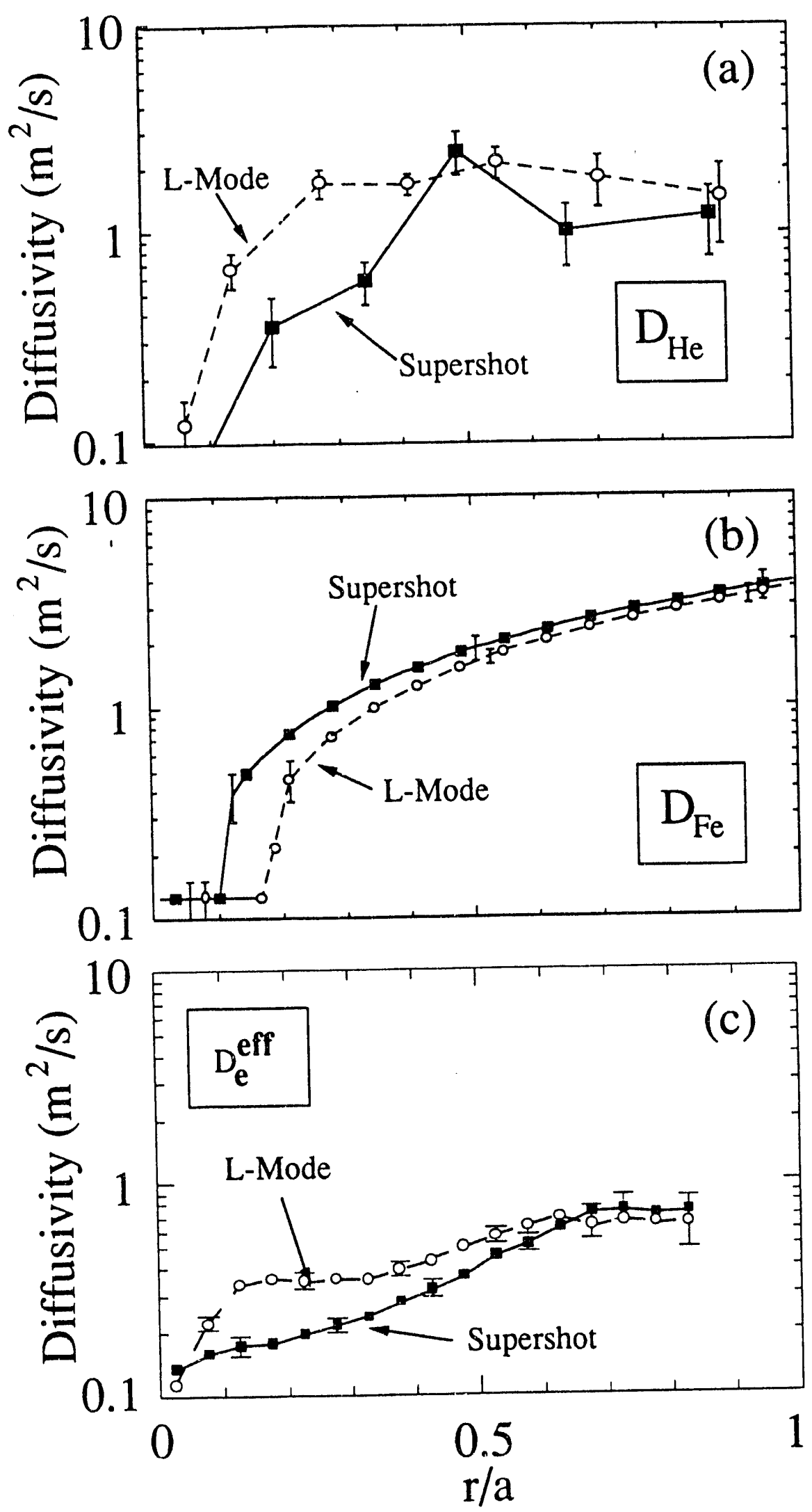

Fig. 6 

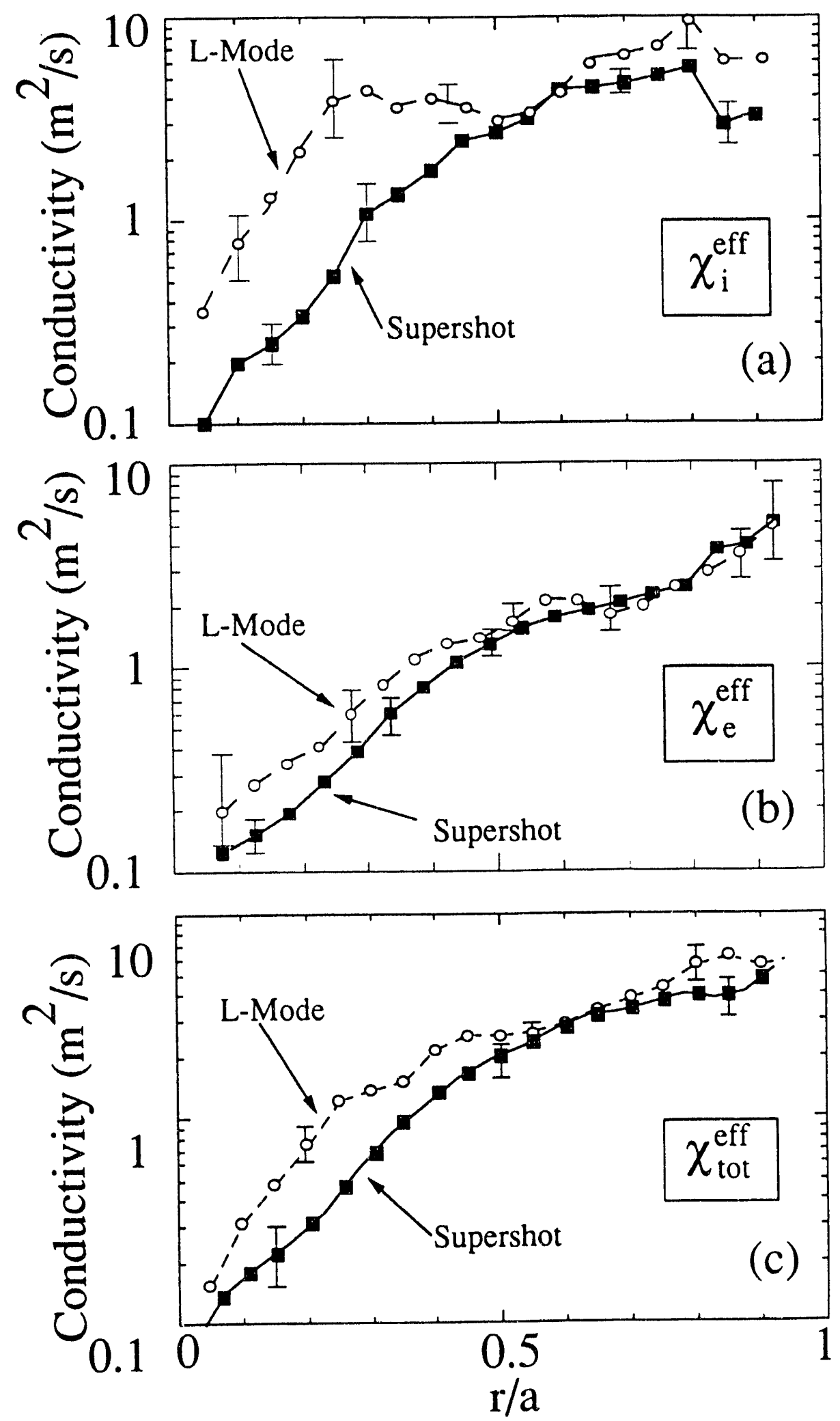

Fig. 7 

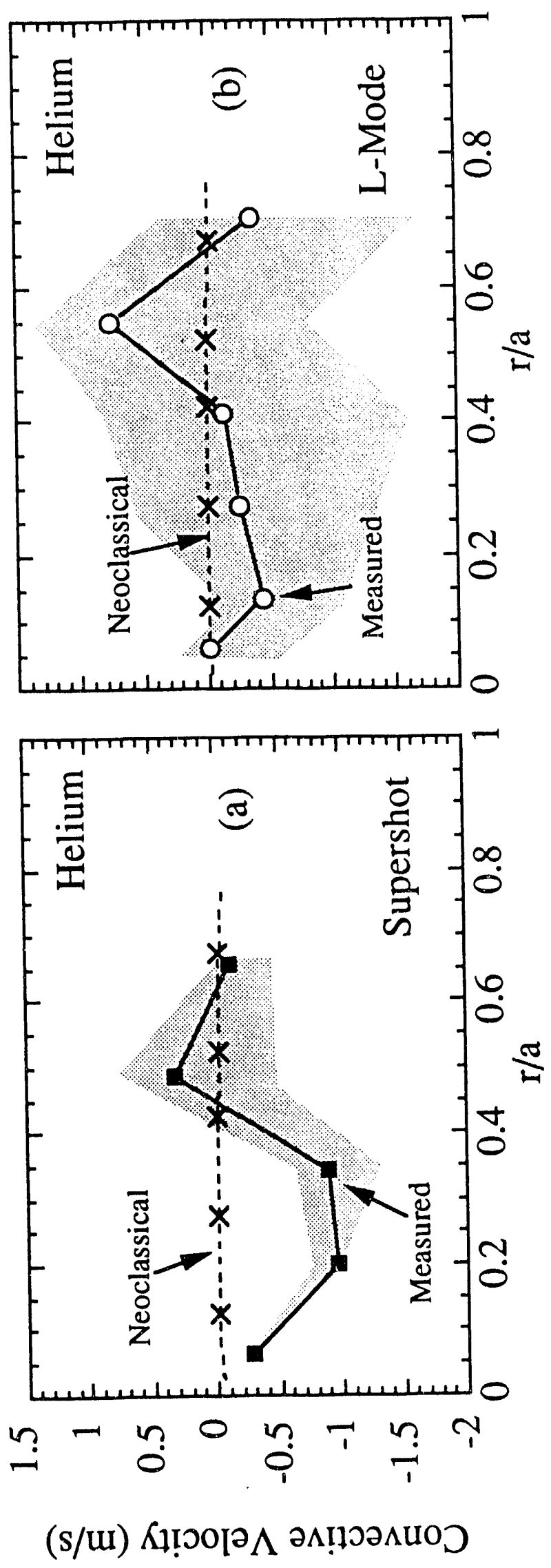

$\stackrel{x}{\dot{x}}$ 


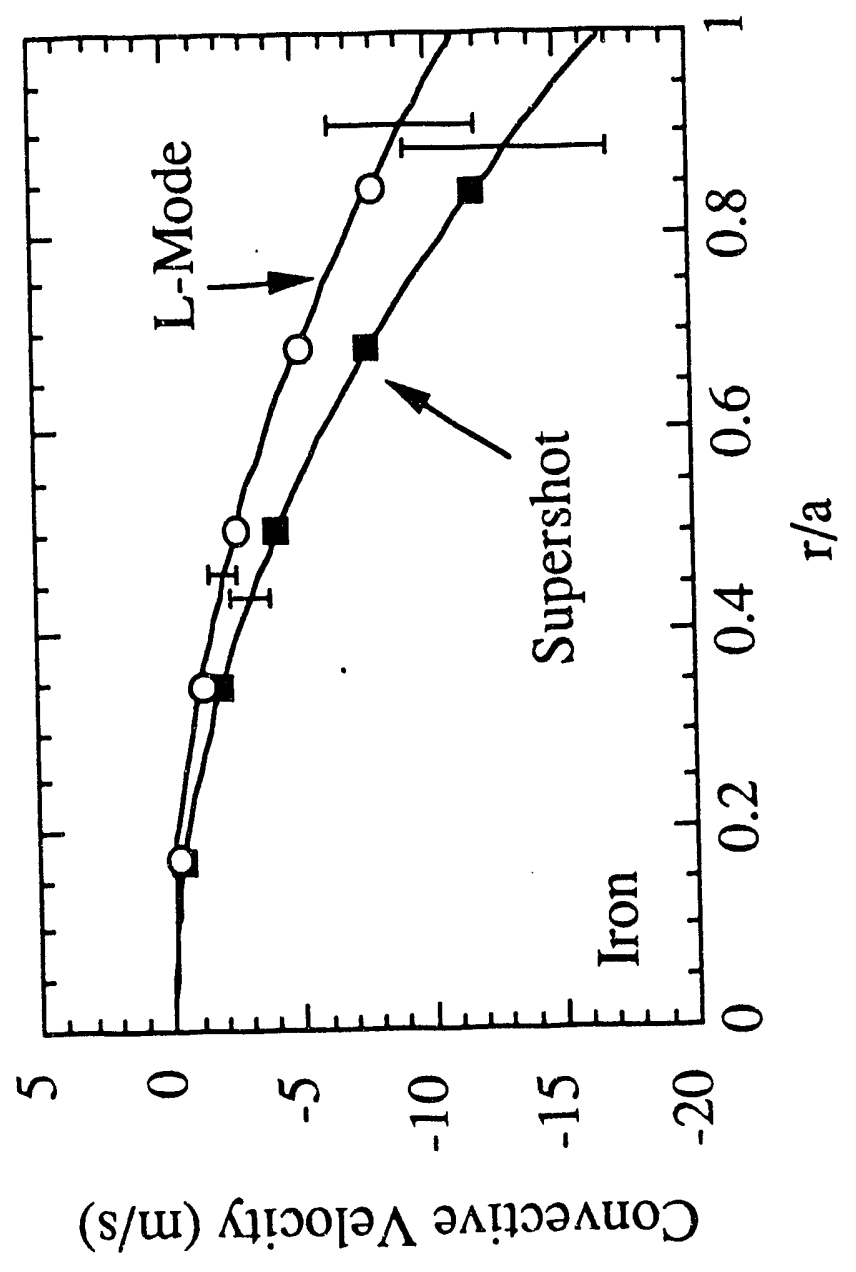



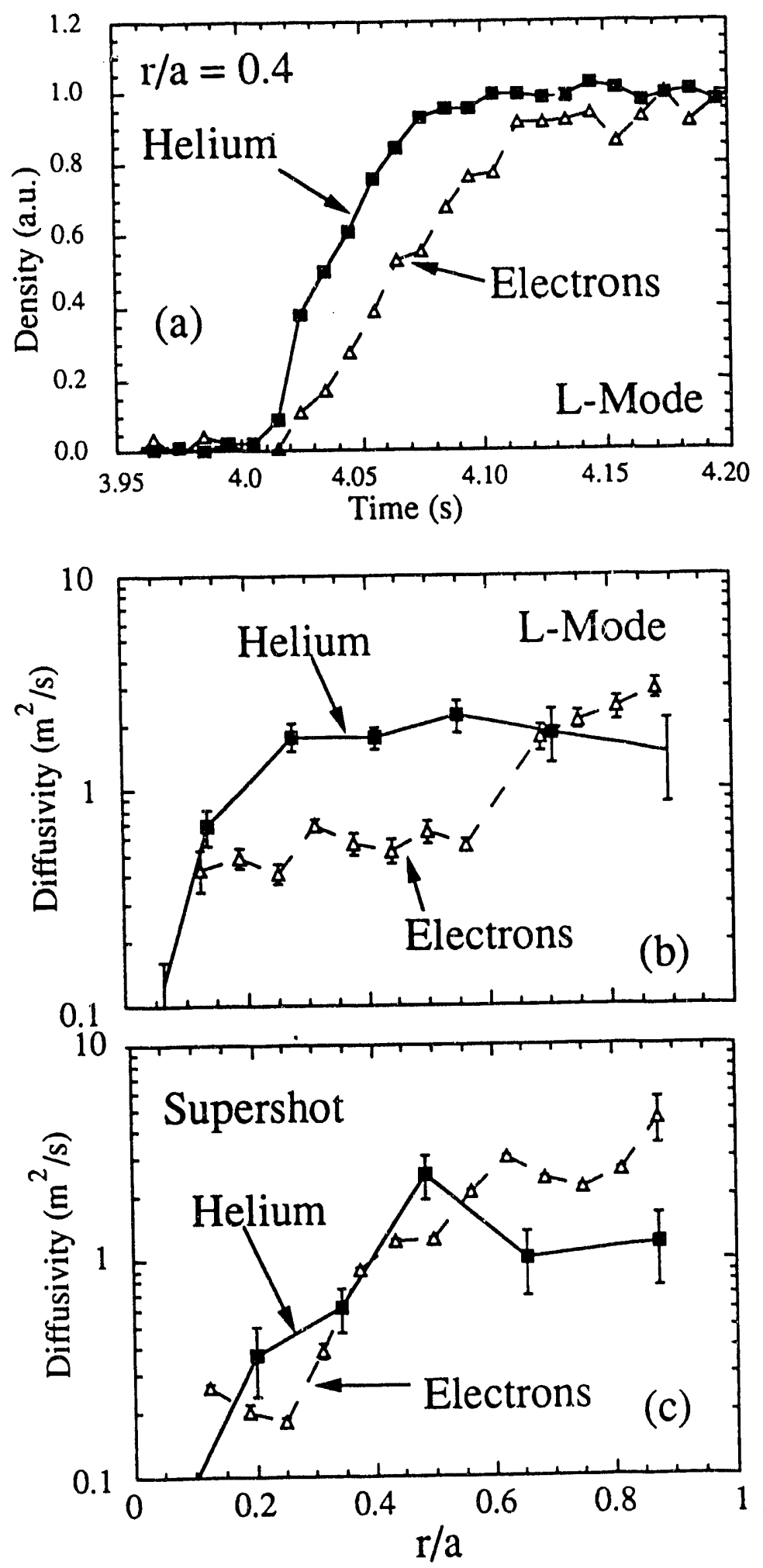

Fig. 10 

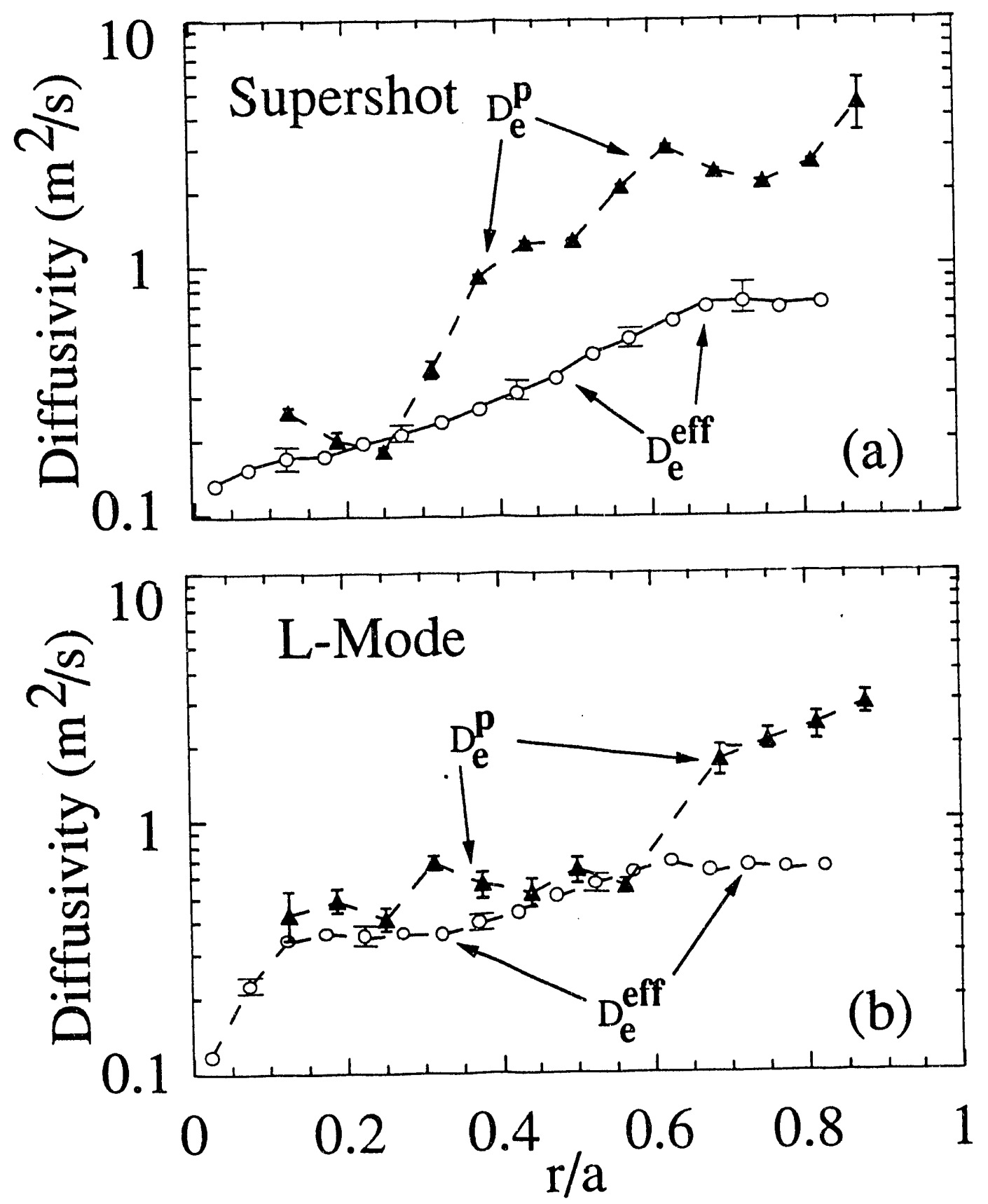

Fig. 11 


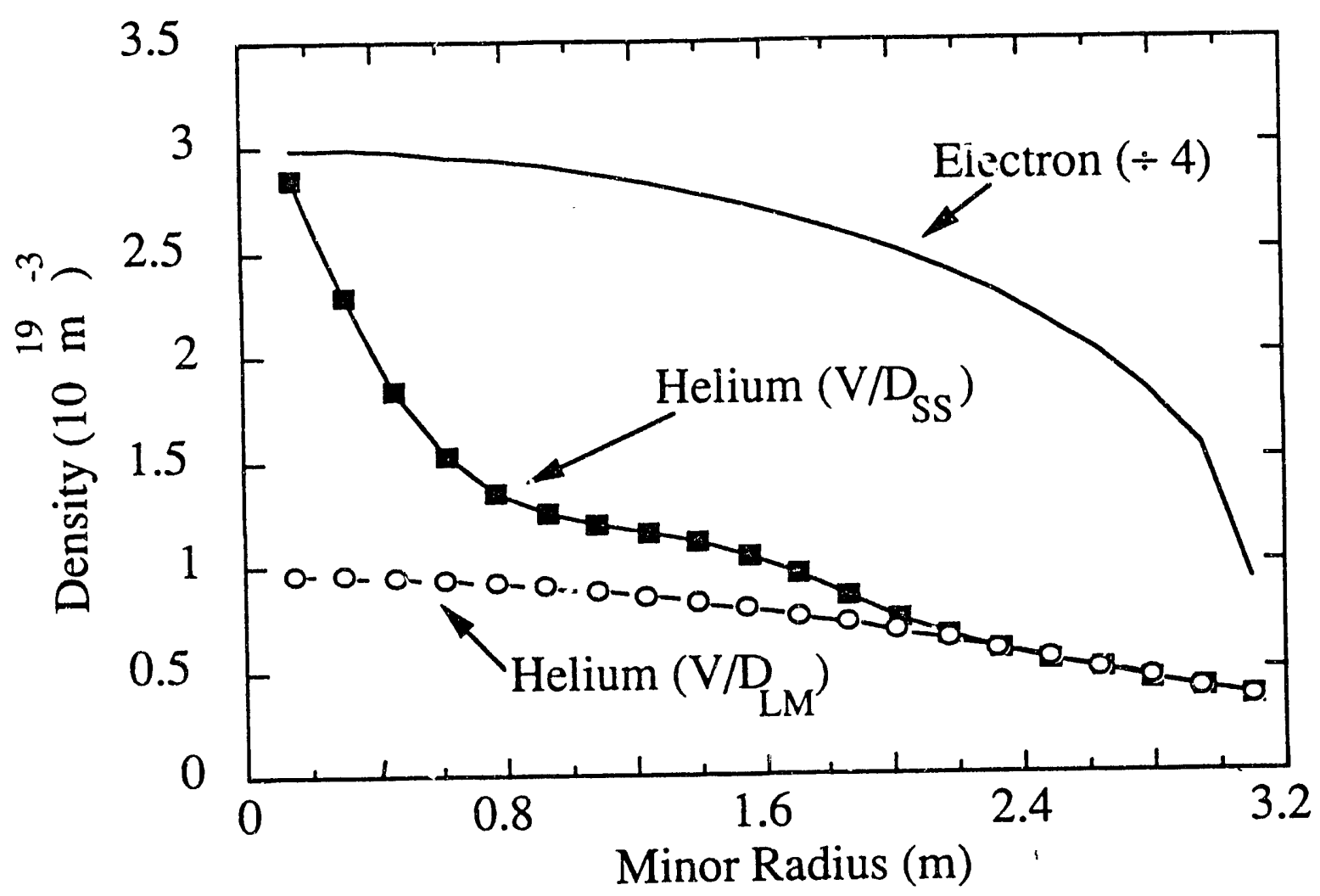

Fig, 12 
Dr. F. Paoloni, Univ. of Wollongong. AUSTRALIA

Prof. M.H. Brennan, Univ. of Sydnoy, AUSTRALIA

Plasma Precearch Lob., Austratien Nal Univ., AUSTRALIA

Prof. I.R. Jones, Flinders Univ, AUSTRALIA

Prof. F. Cap, Inst for Theoretical Physics. AUSTRIA

Prof. M. Heindler, Institut for Theoretische Physik, AUSTRIA

Prof. M. Gooseens, Astronomisch Instituut, BELGIUM

Ecole Proyde Niturio, Lab. do Phy. Plaemas, BELGIUM

Commission-Europaen, DG. XII-Fusion Proo., BELGIUM

Prof. R. Bouciqub, Rijkeunimeritait Gent, BELGIUM

Dr. P.H. Seknaten, Instituto Fisica, BPAZIL

Instituto Neciond Do Pecopieas Eepacieie-INPE, BRWZIL

Documents Olice, Atomic Energy of Cenada Ld., CANADA

Dr. M.P. Bectynakj, MPQ Technologies, Inc., CANADA

Dr. H.M. Skaregard, Univ. of Sackatchowen, CANADA

Prof. J. Teichmam, Univ. of Montreal, CANADA

Prof. S.R. Srenivasen, Univ. of Celgary, CANADA

Prof. T.W. Johnston, INAS-Energie, CANADA

Dr. R. Bolton, Centre canadien de fusion magnátique, CANADA

Dr. C.R. James., Univ. of Aberta. CANADA

Dr. P. Lukic, Komonsketho Universzit, CZECHOSLOVAKIA

Tho Librarian, Cutham Luboritory. ENGLAND

Librey. R61, Ruthertord Applewon Laboratory, ENGLAND

Mrs. S.A. Hutchinson, JET Library, ENGLAilo

Dr. S.C. Shema, Univ. of South Pecific, FIJI ISLANDS

P. Mahomen, Univ. of Heleinhi, FINLAND •

Prof. M.N. Buseac, Ecolo Potylachnique, FRANCE

c. Mourtat, Leb. de Physique des Milioux lonises. FRANCE

J. Radot, CENMADARACHE - Bat 506, FPANCE

Prof. E. Economou, Univ. of Crow, GFEECE

Ms. C. Rinni, Univ. of loannina, GREECE

Dr. T. Mud, Acadomy Bibliographic Ser., HONG KONG

Preprint Librery, Hungarian Acedemy of Sa., HUNGARY

Dr. B. DasGupea, Saha inst of Nucleer Physics, INDIA

Dr. P. Kaw, Inst. for Piasma Rosearch, INDIA

Dr. P. Roseney, lereat Inst of Tectinology, ISPAEL

Librerien, Intermationd Centor for Theo Physics. ITALY

Miss C. Do Pab, Associnzion EURATOMAENEA, ITALY

D. G. Grosso, Istituto of Ficica dal Plasma, ITALY

Prof. G. Rostenoni, istituro Gas lonizzeti Dol Cnr, ITALY

Dr. H. Yumato, Tochibe Ras a Down Center, JAPAN
Prof. I. Kawakemi, Hiroshima Univ., JAPAN

Prot. K. Nishikawa, Hiroshima Univ., JAPAN

Director, Japen Atomic Energy Research Inst., JAPAN

Prof. S. Itoh, Kyushu Univ., JAPAN

Reseerch Info. Ctr., National Instit. for Fusion Science, JAPAN

Prof. S. Tenekn, Kyoto Univ., JAPAN

Librery, Kyow Univ., JAPAN

Prof. N. Inown, Univ. of Tokyo, LAPAN

Socrotary, Plasma Section, Electrobchnical Lab. JAPAN

S. Mori, Technical Advisor, LAERI, LAPAN

Dr. O. Miteri, Kemanoto Inst of Technology, JAPAN

J. Hyeon-Sook, Koma Abmic Enorgy Rosearch Inst, KOREA

D.I. Chai, The Koren Ady. Inst. of Sai. \& Tect., KOREA

Prof. B.S. Liby, Univ. of Waikato, NEW ZEALAND Inst of Phyeics, Chinese Acad Sa PEOPLE'S REP. OF CHINA Librey. Inst of Plasma Physics, PEOPLE'S REP. OF CHINA Teinghua Univ. Libray, PEOPLE'S REPUBLIC OF CHINA Z. Li, S.W. Inst Phytica, PEOPLE'S REPUBUC OF CHINA Prol. J.A.C. Cebre, Instituto Superior Tecrico, PORTUGAL Dr. O. Potrus. Al I Cuza Univ., ROMANIA

Dr. J. do Villiers, Fusion Studies, AEC, S. AFRICA

Prol. M.A. Hewborg. Univ. of Natal, S. AFRICA

Prol. D.E. Kim, Pohang inst. of Sci. \& Tech., SO. KOREA

Prof. C.I.E.M.A.T, Fucion Division Library, SPAIN

Dr. L Stanflo, Univ. of UAEA, SWEDEN

Librery, Royd Inet. of Tectmology, SWEDEN

Prot. H. Whetmeon, Chwmors Univ. of Tech., SWEDEN

Centro Phys. Des Plasenas, Ecole Potytech, SWITZERLAND Bibliotheak, Inst. Voor Plasma-Fycica, THE NETHERLANDS

Asst. Prot. Dr. S. Cakir, Midde East Tech. Univ., TURKEY

Dr. V.A. Guthilth,Sci. Res. Inot. Electrophys.I Apparatus, USSR

Dr. D.D. Ayutov, Siberian Brench of Academy of Sa., USSR

Dr. G.A. Eliceon, I.V. Kurchatov Inst, USSR

Librerien, The Ukr.SSR Academy of Scionces, USSR

Dr. LM. Kovizhnykh, Inst. of Goneral Physics. USSR

Kemtorechungeaniege GmbH, Zentrabibliothek, W. GERMANY

Bibliothek, Inst. For Plasmatorschung, W. GERMANY

Prof. K. Schinder, Ruhr-Universitat Bochum, W. GERMANY

Dr. F. Weoner, (ASDEX), Max-Piandk-institut. W. GERMANY

Litorarian, Max-Plenck-Institur, W. GERMANY

Prol. R.K. Janev, inst of Physics, Yugoslavia 

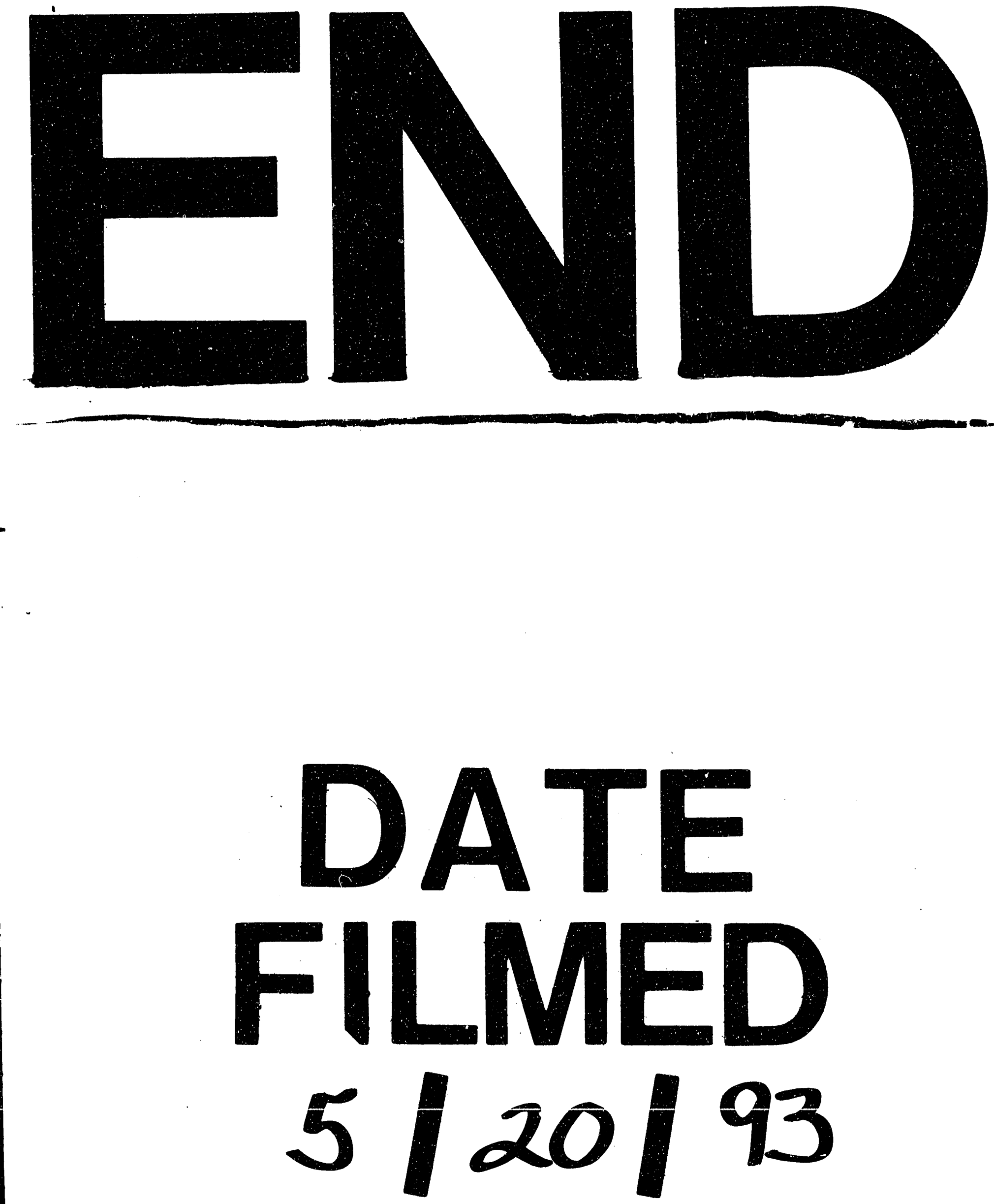
